\title{
The diverse radiodont fauna from the Marjum Formation of Utah, USA (Cambrian: Drumian)
}

\author{
Stephen Pates ${ }^{\text {Corresp.. Equal first author, } 1}$, Rudy Lerosey-Aubril ${ }^{\text {Corresp.. Equal first author, } 1}{ }^{1}$, Allison C Daley ${ }^{2}$, Carlo Kier $^{3}$, Bonino Enrico ${ }^{3}$ \\ , Javier Ortega-Hernández ${ }^{1}$ \\ ${ }^{1}$ Museum of Comparative Zoology and Department of Organismic and Evolutionary Biology, Harvard University, Cambridge, Massachusetts, United States \\ 2 Institut des sciences de la Terre (ISTE), Université de Lausanne, Lausanne, Vaud, Switzerland \\ 3 Back to the Past Museum, Carretera Cancún, Quintana Roo, Mexico \\ Corresponding Authors: Stephen Pates, Rudy Lerosey-Aubril \\ Email address: stephenpates@fas.harvard.edu, rudy_lerosey@fas.harvard.edu
}

Radiodonts have long been known from Cambrian deposits preserving non-biomineralizing organisms. In Utah, the presence of these panarthropods in the Spence and Wheeler (House Range and Drum Mountains) biotas is now well-documented. Conversely, radiodont occurrences in the Marjum Formation have remained scarce. Despite the large amount of work undertaken on its diverse fauna, only one radiodont (Peytoia) has been reported from the Marjum Biota. In this contribution we quadruple the known radiodont diversity of the Marjum fauna, with the description of the youngest members of two genera, Caryosyntrips and Pahvantia, and that of a new taxon Buccaspinea cooperi gen. et sp. nov. This new taxon can be identified from its large oral cone bearing robust hooked teeth with one, two, or three cusps, and by the unique endite morphology and organisation of its frontal appendages. Appendages of at least 12 podomeres bear six recurved plate-like endites proximal to up to four spiniform distal endites. Pahvantia hastata specimens from the Marjum Formation are particularly large, but otherwise morphologically indistinguishable from the carapace elements of this species found in the Wheeler Formation. One of the two new Caryosyntrips specimens can be confidently assigned to $C$. camurus. The other bears the largest spines relative to appendage length recorded for this genus, and possesses endites of variable size and unequal spacing, making its taxonomic assignment uncertain. Caryosyntrips, Pahvantia, and Peytoia are all known from the underlying Wheeler Formation, whereas isolated appendages from the Spence Shale and the Wheeler Formation, previously assigned to Hurdia, are tentatively reidentified as Buccaspinea. Notably, none of these four genera occurs in the overlying Weeks Formation, providing supporting evidence of a faunal restructuring around the Drumian-Guzhangian boundary. The description of three additional nektonic taxa from the Marjum Formation further documents the higher relative proportion of free-swimming species in this biota compared 
to those of the Wheeler and Weeks Lagerstätten. This could be related to a moderate deepening of the basin and/or changing regional ocean circulation at this time. 
1 The diverse radiodont fauna from the Marjum Formation of Utah, USA (Cambrian:

\section{Drumian)}

3

4 Stephen Pates $^{1 *}$, Rudy Lerosey-Aubril ${ }^{1 *}$, Allison C. Daley ${ }^{2}$, Carlo Kier $^{3}$, Enrico Bonino ${ }^{3}$ \&

5 Javier Ortega-Hernández ${ }^{1}$

$7{ }^{1}$ Museum of Comparative Zoology and Department of Organismic and Evolutionary Biology,

8 Harvard University, Cambridge, Massachusetts, USA.

$9{ }^{2}$ Institut des sciences de la Terre (ISTE), Université de Lausanne, Lausanne, Vaud, Switzerland.

$10{ }^{3}$ Back to the Past Museum, Carretera Cancún, Puerto Morelos, Quintana Roo, Mexico.

$11 *$ These authors equally contributed to this paper

13 Corresponding authors:

14 Stephen Pates, stephenpates@,fas.harvard.edu;

15 Rudy Lerosey-Aubril, rudy_lerosey@fas.harvard.edu

16

17 


\section{Abstract}

19 Radiodonts have long been known from Cambrian deposits preserving non-biomineralizing

20 organisms. In Utah, the presence of these panarthropods in the Spence and Wheeler (House

21 Range and Drum Mountains) biotas is now well-documented. Conversely, radiodont occurrences

22 in the Marjum Formation have remained scarce. Despite the large amount of work undertaken on

23 its diverse fauna, only one radiodont (Peytoia) has been reported from the Marjum Biota. In this

24 contribution we quadruple the known radiodont diversity of the Marjum fauna, with the

25 description of the youngest members of two genera, Caryosyntrips and Pahvantia, and that of a

26 new taxon Buccaspinea cooperi gen. et sp. nov. This new taxon can be identified from its large

27 oral cone bearing robust hooked teeth with one, two, or three cusps, and by the unique endite

28 morphology and organisation of its frontal appendages. Appendages of at least 12 podomeres

29 bear six recurved plate-like endites proximal to up to four spiniform distal endites. Pahvantia

30 hastata specimens from the Marjum Formation are particularly large, but otherwise

31 morphologically indistinguishable from the carapace elements of this species found in the

32 Wheeler Formation. One of the two new Caryosyntrips specimens can be confidently assigned to

33 C. camurus. The other bears the largest spines relative to appendage length recorded for this

34 genus, and possesses endites of variable size and unequal spacing, making its taxonomic

35 assignment uncertain. Caryosyntrips, Pahvantia, and Peytoia are all known from the underlying

36 Wheeler Formation, whereas isolated appendages from the Spence Shale and the Wheeler

37 Formation, previously assigned to Hurdia, are tentatively reidentified as Buccaspinea. Notably, 
38 none of these four genera occurs in the overlying Weeks Formation, providing supporting

39 evidence of a faunal restructuring around the Drumian-Guzhangian boundary. The description of

40 three additional nektonic taxa from the Marjum Formation further documents the higher relative

41 proportion of free-swimming species in this biota compared to those of the Wheeler and Weeks

42 Lagerstätten. This could be related to a moderate deepening of the basin and/or changing

43 regional ocean circulation at this time.

45 Keywords: Panarthropoda, Hurdiidae, Buccaspinea, Caryosyntrips, Pahvantia, Peytoia, Pelagic

46 lifestyle, Miaolingian, Exceptional preservation.

\section{Introduction}

49 Fossil deposits that preserve the remains of both biomineralizing and non-biomineralizing

50 organisms provide key insights into the evolution and ecology of life on Earth not accessible

51 from the shelly fossil record alone. Such exceptional strata, or Konservat-Lagerstätten, have been

52 discovered in Cambrian deposits on all major Cambrian palaeocontinents. Most Konservat-

53 Lagerstätten are known from China and North America (Muscente et al. 2017), and although

54 these deposits are not equally prolific in terms of taxonomic diversity and fossil abundance

55 (Gaines, 2014), suffer from different taphonomic biases (Saleh et al. 2020), and vary at both regional and continental scales (Holmes et al. 2018; Fu et al. 2019; Nanglu et al. 2020), they provide congruent pictures of how bilaterian animals diversified, became ecologically 
58 significant, and profoundly influenced marine environments at that time (Budd \& Jensen, 2000;

Butterfield, 2011, 2018; Erwin \& Tweedt, 2012; Mángano \& Buatois, 2014, 2020; Daley et al.

60 2018). The most abundant and diverse group of these early bilaterians were total-group

61 euarthropods, relatives of modern arachnids, crustaceans, insects, and myriapods. Iconic in

62 Paleozoic exceptionally-preserved faunas, stem-group euarthropods (sensu Ortega-Hernández,

63 2016) such as 'gilled-lobopodians' and radiodonts have proved critical for our understanding of

64 the early evolution of the phylum (Budd, 1998; Daley, 2013; Daley et al. 2009, 2018; Cong et al.

65 2014; Vannier et al. 2014; Van Roy et al. 2015; Young \& Vinther, 2017).

66 Radiodonts - a diverse extinct group that includes Anomalocaris and its relatives - have

67 long been known as comparatively common elements in Cambrian Konservat-Lagerstätten, but an ever-growing body of evidence shows that these organisms occupied a variety of ecological niches and contributed in different ways to the diversity of early animal communities (Daley \& Budd, 2010; Daley \& Edgecombe 2014; Vinther et al. 2014; Van Roy et al. 2015; Lerosey-Aubril \& Pates, 2018; Liu et al. 2018; Moysiuk \& Caron, 2019). Radiodonts greatly differed in size, ranging from millimetres to meters in length (Van Roy et al. 2015; Lerosey-Aubril \& Pates, 2018; Liu et al. 2018; Pates et al. 2020), and had variable body shapes that impacted their swimming capabilities. Radiodonts are typically reconstructed as nektonic animals (also referred to as 'free swimmers' hereafter), with the possible exception of the eudemersal Cambroraster cephalic sclerites (amplectobeluids and anomalocaridids; Daley \& Edgecombe, 2014; Cong et al. 
78

2014, 2016, 2017, 2018; Liu et al. 2018) were likely more agile swimmers than those with comparatively reduced, but paired flaps, and cylindrical bodies made semi-rigid by the presence of an elongate cephalic carapace (e.g. the hurdiid Aegirocassis and Hurdia; Daley et al. 2009, 2013; Van Roy et al. 2015). Swimming power has been shown to increase with the size of swimming flaps (Usami, 2006), which are more developed in amplectobeluids and anomalocaridids. These two families of inferred ambush predators also differ from hurdiids by the presence of a large tail fan, a structure that increases manoeuvrability and reduces turning radii, as demonstrated by experimental fluid dynamics (Sheppard et al. 2018). Hurdiids may have been adapted for agile swimming at lower speeds, based on the presence of paired body flaps, with the ventral flaps interpreted as being used mainly for propulsion, and the dorsal flaps providing stability and steering particularly during the sustained gliding that likely characterised the swimming motion in suspension feeding taxa (e.g. Aegirocassis, Pahvantia) (Van Roy et al. 2015; Lerosey \& Pates 2018).

This interpretation of radiodonts as ecologically diverse components of early Paleozoic faunas finds additional support in the recent realization that many Cambrian KonservatLagerstätten host several representatives of this major group. For instance, radiodonts are represented by at least nine genera in Chengjiang (all localities together; Zeng et al. 2018, tab. S1; Cong et al. 2018; Guo et al. 2019; Liu et al. 2020), seven genera in the Burgess Shale (Moysiuk \& Caron, 2019; Zeng et al. 2018, tab. S1) - three to five of them occurring in the most studied localities (Daley \& Budd, 2010; Daley et al. 2013; O’Brien \& Caron, 2016) -, and four 
98 genera in the Kinzers Formation (Pates \& Daley, 2019). Such co-occurrences are made possible

99 by the occupation of different ecological niches, but also reflect patchiness in the preservation of

100 palaeocommunities within these deposits (Nanglu et al. 2020). Recent studies in Utah, the home

101 of five Cambrian Konservat-Lagerstätten (Robison et al. 2015), have increased the known

102 diversity of the radiodont faunas in the Spence Shale (three genera; Briggs et al. 2008; Pates \&

103 Daley, 2017; Pates et al. 2018a), the Wheeler Formation in the Drum Mountains (three genera;

104 Halgedahl et al. 2009, fig. 10L; Pates \& Daley, 2017; Lerosey-Aubril \& Pates, 2018), and

105 especially the Wheeler Formation in the House Range (at least six genera; Briggs et al. 2008;

106 Pates et al. 2017, 2018a, b; Lerosey-Aubril et al. 2020a). Only one radiodont genus

107 (Anomalocaris) has as-yet been reported from the Weeks Formation (Lerosey-Aubril et al. 2014),

108 but this is the least explored and the youngest of the Cambrian Konservat-Lagerstätten of Utah

109 (Lerosey-Aubril et al. 2018). By contrast, the Marjum Formation has received considerable

110 attention by both professional and amateur palaeontologists over the last 50 years (e.g. Robison,

111 1991; Bonino \& Kier, 2010; Conway-Morris et al. 2015; Robison et al. 2015), and yet only two

112 specimens of a single radiodont genus, Peytoia, have been described until now (Briggs \&

113 Robison, 1984; Pates et al. 2018a). This is all the more surprising as the Marjum fauna is

114 particularly diverse (over 139 species according to Robison et al. 2015, but see below) with a

115 high proportion of pelagic taxa (more than one third of the generic diversity; see definition of 116 pelagic below). 
117 In this contribution, we report the first occurrences in the Marjum Formation, and the

118 youngest occurrences overall, of the radiodont genera Caryosyntrips and Pahvantia, alongside

119 the description of the new hurdiid Buccaspinea cooperi gen. et sp. nov. Beyond complementing

120 our understanding of these genera, the new data confirm that the Marjum assemblage is

121 proportionally richer in free swimming components than those of the underlying Wheeler and

122 overlying Weeks formations, which might be due to a local increase in bathymetry of the

123 depositional environment, enhanced faunal mixing resulting from changes in ocean circulation,

124 or a combination of these factors.

125

126 Geological setting

127 The new radiodont specimens described in this contribution were collected from the Marjum

128 Formation of the House Range of Utah (Fig. 1). This unit was deposited along the northern

129 seaward margin (now western North America) of the 'Great American Carbonate Bank' (Derby

130 et al. 2012) which encircled Laurentia at this time and separated shallow-water proximal shelf

131 settings from deep-water distal shelf and slope environments. The development of extensive

132 carbonate facies all around Laurentia during the early Cambrian was facilitated by its low-

133 latitude palaeogeographic position (Torsvik \& Cocks, 2017). The Marjum Formation and other

134 Cambrian Lagerstätten from western North America were deposited close to the equator.

135 The Marjum Formation was deposited within the House Range Embayment, a fault-

136 controlled basin that developed during the Wuliuan age and formed a prominent re-entrant 
137 within the offshore margin of the carbonate platform in parts of present-day Nevada and Utah

138 (Hintze \& Robison, 1975; Rees, 1986). This locus of deep-water sedimentation within the Great

139 Carbonate Bank allowed the deposition of a continuous succession of shale-dominated strata

140 typical of the Outer Detrital Belt (sensu Aitken, 1997), namely the Wheeler, Marjum, and Weeks

141 Formations (in ascending stratigraphic order). There is clear evidence for the presence of a

142 gently sloping ramp connecting the deepest part of the embayment to the carbonate platform to

143 the east (now north; Rees, 1986; Foster \& Gaines, 2016). In contrast, the transition between the

144 two areas in the west (now south) might have been abrupt (Rees, 1986). The Marjum Formation

145 crops out in parts of the House Range of Utah, but not in neighbouring ranges. This more limited

146 geographic extent compared to that of the underlying Wheeler Formation (House Range and

147 Drum Mountains) records a general filling of the basin. Reaching up to ca. $430 \mathrm{~m}$ in thickness

148 (Miller et al. 2012), the Marjum Formation is composed of thin-bedded limestone inter-bedded

149 with shale/lime mudstone (Robison, 1964), which have yielded a diverse biota of about 145

150 species (89 genera), of which 30 are entirely non-biomineralizing organisms (Robison et al.

151 2015; this study). This important diversity of the Marjum biota is partially explained by the fact

152 that the unit extends from the Drumian to the Guzhangian through three agnostoid biozones

153 (Ptychagnostus atavus, P. punctuosus, and Lejopyge laevigata biozones; Robison \& Babcock,

154 2011). However, to our knowledge non-biomineralized fossils have only been recovered from

155 the middle part of the unit (P. punctuosus biozone) and accordingly are all Drumian in age. 


\section{Material and methods}

158 The material described in this contribution consists of new specimens from the Marjum

159 Formation, which are deposited in the collections of the Back to the Past Museum (prefix BPM)

160 and the Natural History Museum of Utah (prefix UMNH.IP). Photographs of additional fossils

161 are used for comparative purposes and to illustrate pelagic components of the Marjum fauna-

162 these specimens are housed in the Biodiversity Institute of the University of Kansas (prefix

163 KUMIP), the Department of Geology of the University of Utah (prefix UU), the Natural History

164 Museum of Utah, and the Smithsonian Institution's U.S. National Museum of Natural History

165 (prefix USNM-PAL). Lastly, materials accessioned at the Museum of Comparative Zoology,

166 Harvard University (prefix MCZ) were examined for comparative purposes but not figured.

167 Details for all specimens considered over the course of this study can be found in the

168 Supplementary Data (Pates et al. 2020b, Table S1).

169 Robison et al. 's (2015) comprehensive list of taxa present in the Wheeler (House Range),

170 Marjum, and Weeks Formations was used to create a database to compare the compositions of

171 their exceptionally-preserved faunas with regard to taxonomy and life habits (Pates et al. 2020b,

172 Supplementary Data 3). This dataset was refined using taxonomic lists compiled by R. A.

173 Robison, which detail the compositions of fossil assemblages at most Wheeler, Marjum, and

174 Weeks fossil sites in the House Range of Utah. This enabled us to exclude the taxa that only

175 occur in stratigraphic intervals barren of non-biomineralized fossils, such as the lower and upper

176 parts of the Marjum Formation or the lower part of the Weeks Formation. We then updated the 
177 resulting dataset to include omitted (Caron et al. 2013) or more recently published contributions

178 (Conway Morris et al. 2015; Maletz \& Steiner, 2015; Smith, 2015; Foster \& Gaines, 2016;

179 Pates et al. 2017; Lerosey-Aubril \& Pates, 2018; Lerosey-Aubril \& Skabelund, 2018; Lerosey-

180 Aubril et al. 2018; Pates et al. 2018a, 2018b; Conway Morris et al. 2020; Lerosey-Aubril et al.

$1812020 a, b)$ and some new discoveries (R.L.-A., pers. obs. 2019). Finally, we complemented the

182 database with information on lifestyle for each taxon. Three broad categories of lifestyles were

183 considered: endobenthic (or infaunal), epibenthic (or epifaunal), and pelagic. Benthic (i.e.

184 bottom-dependent) marine animals are regarded as endobenthic or epibenthic if they spend most

185 of their lives inside the seafloor or on top of it, respectively. An epibenthic lifestyle was also

186 assigned to nektobenthic taxa (sensu Whalen \& Briggs, 2018) - animals living on the seafloor,

187 but capable of temporary swimming (e.g. most trilobites). We inferred a pelagic lifestyle for

188 animals thought to have spent most of their life within the water column some distance from the

189 seafloor, either as passive drifters (plankton) or active swimmers (nekton).

$190 \quad$ Fossils were photographed dry or immersed in water, under polarized or cross-polarized

191 illumination, using a Nikon D5500 DSLR fitted with a Nikon 40 mm DX Micro-Nikkor lens or a

192 Canon EOS500D digital SLR Camera fitted with a Canon EF-S 60 mm macro lens. In most

193 cases, images were taken with manual focusing through the focal plane and then stacked using

194 Photoshop CC. Images of counterparts were mirrored to orientate features the same way as in the

195 part, thus facilitating direct comparison between figures/figure elements. Image processing

196 software ImageJ and ImageJ2 were used to make digital measurements (Schneider et al. 2012; 
197 Rueden et al. 2017). Interpretative drawings and figures were constructed using Photoshop CC

198 and Inkscape 0.92.

199 The electronic version of this article in Portable Document Format (PDF) will represent a

200 published work according to the International Commission on Zoological Nomenclature (ICZN),

201 and hence the new names contained in the electronic version are effectively published under that

202 Code from the electronic edition alone. This published work and the nomenclatural acts it

203 contains have been registered in ZooBank, the online registration system for the ICZN. The

204 ZooBank LSIDs (Life Science Identifiers) can be resolved and the associated information viewed

205 through any standard web browser by appending the LSID to the prefix http://zoobank.org/. The

206 LSID for this publication is: urn:1sid:zoobank.org:pub:80914DF2-7D3E-4A02-81DE-

207 156F8E70889E. The online version of this work is archived and available from the following

208 digital repositories: PeerJ, PubMed Central and CLOCKSS.

209

210 Terminology

211 The terminology used in our descriptions broadly follows Guo et al. (2019) and Lerosey-Aubril

212 et al. (2020) for frontal appendages. The term 'plate-like endite' is equivalent to 'blade-like

213 endites' (Guo et al. 2019), 'broad, elongate endites' (Moysiuk \& Caron 2019) and 'elongated

214 ventral spines' (Daley et al. 2013) in other recent works. The term 'distal endites' is used to refer

215 to the simple spiniform endites borne on podomeres distal to those which bear plate-like endites,

216 following Pates et al. (2019). This term is equivalent to 'enditic spines' of Moysiuk \& Caron 
217 (2019). We follow the terminology of Liu et al. (2020) for cephalic carapace elements, Daley \&

218 Edgecombe (2014) for trunk parts, and Daley \& Bergström (2012) for components of the oral

219 cone, with the addition of the term 'tooth' (used in Daley et al. 2013 and Zeng et al. 2018) to

220 describe spines protruding from the inner margins of oral cone plates. Additional terminology

221 relating to the orientation and measurements of Caryosyntrips frontal appendages follows Pates

222 \& Daley (2017). Abbreviations: sag., sagittal; tr., transverse.

223

224 Results

225 Systematic Palaeontology

226 Superphylum PANARTHROPODA Nielsen, 1995

227 Order RADIODONTA Collins, 1996

228 Family HURDIIDAE Lerosey-Aubril \& Pates, 2018

229

230 Type genus. Hurdia Walcott, 1912 (including Proboscicaris Rolfe, 1962).

231

232 Other genera included. Aegirocassis Van Roy et al. 2015, Buccaspinea gen. nov., Cambroraster

233 Moysiuk \& Caron, 2019, Cordaticaris Sun et al. 2020, Pahvantia Robison \& Richards, 1981,

234 Peytoia Walcott, 1911, Stanleycaris Pates et al. 2018b, Ursulinacaris Pates et al. 2019a.

235 Questionably: Schinderhannes Kühl et al. 2009, Zhenghecaris Vannier et al. 2006. 
237 Remarks. The presence of an oral cone made up of plates of different sizes, lightly sclerotized

238 frontal appendages with endites and dorsal spines, and a segmented body covered dorsally by

239 setal structures and bearing triangular lateral flaps allows Buccaspinea to be identified as a

240 radiodont. Within Radiodonta, frontal appendages with five or more plate-like endites are only

241 known in members of one family, and so we assign the new taxon to the Hurdiidae.

material was later reinterpreted as central carapace elements of a hurdiid radiodont, following

244 comparisons with new putative hurdiid carapace elements from the Chengjiang Biota (Zeng et al.

245 2018). The main reasoning included comparisons with other material from the same horizons

246 assigned to a new genus, Tauricornicaris (Zeng et al. 2018). However, articulated material of

247 Tauricornicaris latzione, the type species of this genus, demonstrated the presence of articulated

248 tergites in this animal, which indicates a more crownward position in the euarthropod lineage

249 than radiodonts - Tauricornicaris is not a hurdiid (Cong et al. 2018). This insight in turn led to

250 uncertainty of the reassignment of Zhenghecaris to Hurdiidae. Nevertheless, Zhenghecaris was

251 included in a recent phylogenetic analysis aimed at understanding the internal relationships of

252 Radiodonta (Moysiuk \& Caron 2019); there, Zhenghecaris was interpreted as central carapace

253 elements with posterolateral spinose processes, and its position was resolved as the sister to

254 Cambroraster. The precise systematic position of Zhenghecaris remains uncertain pending the

255 discovery of more material that supports radiodont affinities, such as an association with lateral

256 carapace elements or frontal appendages, as similar evidence has recently supported the 
257 identification of the previously enigmatic Pahvantia as a hurdiid radiodont (Lerosey-Aubril \& 258 Pates, 2018). ward position relative to Radiodonta, with the support of a phylogenetic analysis (Kühl et al. 2009). More recent studies have supported its identification as a radiodont within a monophyletic

262 Hurdiidae (Cong et al. 2014; Van Roy et al. 2015; Lerosey-Aubril \& Pates, 2018; Moysiuk \&

263 Caron, 2019). Its frontal appendages show a comparable organization to hurdiids, but the

264 presence of articulated appendages in the trunk constitutes a major departure from radiodont

265 body plans. Detailed information is still lacking on the structure of the oral cone, presence or 266 absence of dorsal flaps, along with finer details of the frontal appendages, body, and tail, all of

267 which could provide additional support for a radiodont/hurdiid affiliation, or alternative 268 assignment, and so it is left as a questionable member of the family pending future redescription.

Genus Buccaspinea nov. 
277 Diagnosis. Hurdiid radiodont exhibiting the following unique combination of characters: oral

278 cone composed of large and small plates bearing large hooked teeth and surrounding a square

279 central opening ; frontal appendages attach lateral to oral cone and possess at least 12

280 podomeres; six unpaired recurved plate-like endites at least five times longer than the podomeres

281 to which they attach, proximal to considerably shorter (one to two times as long as the height of

282 the podomere to which they attach), spiniform distal endites; auxiliary spines on plate-like

283 endites long and robust, projecting distally; at least 10 trunk segments which do not markedly

284 taper posteriorly; setal structures and broad lateral triangular flaps with transverse lines across

285 their width.

286

287 Etymology. From the Latin 'bucca' (mouth) and 'spinea' (spiny, thorny), a reference to the 288 distinctive large oral cone bearing large thorn-like teeth for this new taxon.

Type material, locality, horizon. The holotype specimen, BPM 1108 (part and counterpart), an

291 almost complete body lacking carapace elements and compressed in oblique-lateral orientation.

292 This specimen was collected in the Drumian strata (Ptychagnostus punctuosus Biozone) of the

293 middle Marjum Formation at the Kells Knolls locality (Fig 1.; locality 1 of Rigby et al. 2010;

294 GPS: 39.270709, -113.283868) in the House Range, Millard County, Utah. 
296 Additional specimens. Three isolated frontal appendages flattened in lateral orientation are

297 tentatively assigned to this new taxon. UU18056.34 was recovered from the slightly older

298 Drumian Ptychagnostus atavus Biozone of the upper Wheeler Formation at the 'New Dig

299 Quarry' (GPS: 39.35883333, -113.27861111) in the House Range, Millard County, Utah

300 (Lerosey-Aubril et al. 2020a). KUMIP 314040 and ROM 59634 originate from the Wuliuan

301 Spence Shale Member (Ptychagnostus praecurrens Biozone) of the Langston Formation at the

302 Miners Hollow locality (GPS: 41.6023, -112.0334), Wellsville Mountains, Box Elder County,

303 Utah (Daley et al. 2013, fig. 24C; Pates et al. 2018a, fig 2.3, 2.4).

304

305 Buccaspinea cooperi sp. nov.

306 urn:lsid:zoobank.org:act:80DC43C1-E1A5-4B20-9D7B-D4116122DB85

307 Figures 2-6 [Figure 2 nearby]

308

309 Diagnosis. As for genus, by monotypy.

310

311 Etymology. The species name 'cooperi' honours Jason Cooper, who discovered the specimen and

312 made it available for study.

313

314 Description. Specimen BPM $1108(\mathrm{a} / \mathrm{b})$ is a near-complete radiodont body composed of an oral

315 cone, paired frontal appendages, trunk segments, lateral flaps and setal structures, which are 
316 preserved in dorsolateral view (Figs. 2, 3). Only the oral cone and frontal appendages are

317 preserved from the head region, and the posterior of the body is not preserved. No eyes, cephalic

318 carapace elements, or internal organs are visible. The specimen measures c. $100 \mathrm{~mm}$ (sag.) from

319 the posterior tip of the body to the anterior margin of the oral cone, with the latter structure

320 representing one-quarter of the preserved length (sag.).

321

The oral cone (oc, Figs. 2, 3) is preserved flattened approximately dorsoventrally, and

322 positioned anterior to the trunk. It includes large and small plates (lp, sp, Figs. 4, 5), all bearing

323 prominent multi-pointed teeth along their inner margins. These teeth measure $1-3 \mathrm{~mm}$ from base

324 to tip, being largest at the midpoint of each side of the square opening and decreasing in size

325 towards the corners (t, Figs. 4, 5). Each plate bears a tooth with one, two, or three points. For the

326 three-pointed teeth, a large central point is flanked by two smaller points (e.g. white and black

327 arrows in Fig. 6A). Teeth are only visible on two of four internal margins of the central opening.

328 This is due to the slightly oblique orientation of preservation of the oral cone, which has also

329 been compacted as indicated by the overlapping teeth towards the corner of the square opening.

330 The boundaries between the plates in the oral cone are not clear or consistently preserved enough

331 on either part to allow the precise arrangement (e.g. triradial, tetraradial) and number of

332 large/small plates to be determined. However, the clear corner and two straight sides visible in

333 the bottom right region of the central opening are of typical tetraradial arrangement (Fig. 4, 5). In

334 the counterpart, one large plate is visible in the centre of the top row, with smaller plates visible

335 towards both top left and top right corners (lp, sp, Fig. 5). An additional structure is present 
336 within the main square opening. This structure, which is fragmented and incomplete, abuts the

337 oral cone along the upper margin of the central opening, and is unlikely to be part of the

338 radiodont mouthparts (om, Figs. 2-5).

339 One frontal appendage is present on each side of the oral cone, with the plate-like

340 endites facing each other (lfa, rfa, Figs. 2, 3). Both frontal appendages are preserved at a slight

341 oblique angle and exhibit podomere boundaries visible as simple lines. The latter allow the

342 recognition of at least 12 podomeres in the left appendage (pd12, Fig. 4); adjacent to the oral

343 cone, a patch of fossil material is tentatively interpreted as the proximal-most part of the shaft

344 region of the appendage (s?, Fig. 4). Only the dorsal margin of the left appendage is visible in the

345 counterpart (1fa, Fig. 5). The total number of podomeres for the right appendage cannot be

346 determined with certainty. At least six large curved, overlapping plate-like endites (en1-6) are

347 delimitated by faint lines on each appendage (en, Figs. 4, 5, 6B; Supplementary Fig. 1). These

348 endites are incomplete in the right appendage, partly due to preparation work that has revealed

349 the outline of the oral cone; when complete, they become progressively shorter towards the distal

region of the appendage and their tips are curved (left frontal appendage, Fig. 4). En6 on both

351 appendages bears robust and elongate distally facing auxiliary spines (aux, Figs. 4, 5), the

352 longest of which measure $5.5 \mathrm{~mm}$ (right frontal appendage) and $6.5 \mathrm{~mm}$ (left frontal appendage)

353 (black arrows, Fig. 4A). On the right appendage, some of those spines belong to more proximal

354 endites and protrude from underneath the distalmost endite (Fig. 6B). Large auxiliary spines can

355 be seen towards the tip of all endites for the left appendage, with the exception of the proximal- 
356 most endite. On en6 of the right appendage (Figs. 4, 5, 6B), it can be observed that these spines

357 generally decrease in width and length towards the tip of the endite. Distal to en6 on the same

358 appendage, four much shorter, spiniform endites lacking auxiliary spines can be seen, including a

359 particularly short or incomplete distalmost one (de, Figs. 4, 5; white arrows, Fig. 6B). Due to the

360 curvature of the appendage, these spiniform endites overlie en6, but they can be distinguished

361 from the similarly-sized auxiliary spines attached to this endite by their orientation: the auxiliary

362 spines are perpendicular to the endite to which they attach, whereas these distal endites are not

363 (Fig. 6B). A single of these distal endites is clearly visible on the left appendage (de, Figs. 4, 5).

364 Small triangular dorsal spines are rare but visible on both left and right appendages (ds, Fig. 4)

365 on at least podomeres 5,9,10 and 11, suggesting they were likely present along the entire length

366 of the appendage. The base of the terminal spine can be seen on the left appendage (ts, Fig. 4),

367 and the counterpart of the right appendage (ts, Fig. 5). The complete spine is visible only in the

368 right appendage of the part and appears to be long $(6.5 \mathrm{~mm})$ and straight, but for a slight kink

369 towards the distal end (ts, Fig. 4). However, it is possible that the morphology of this spine has

370 been obscured by an algal or cyanobacterial filament, because algal or cyanobacterial strands of

371 comparable width can be identified wrapped around dorsal spines of the left appendage (pink

372 strands, Fig. 4), as well as intertwined with some auxiliary spines.

The body, which is incomplete at the posterior, curves towards its left from posterior to

374 anterior and does not appear to taper significantly along its preserved length. The number of

375 segments in the trunk cannot be determined from the central region alone, but counting the flaps 
376 and the bands of setal structures suggests that it is composed of 11 , possibly 12 of them

377 (alternating color bands, Figs. 2 and 3).

378

The anterior three segments appear slightly narrower (tr.) than the rest of the body, as

379

suggested by a comparison of the flap size. The lateral flaps are broad and triangular, and they

380

bear transverse lines running parallel to their long axes over their entire surface (Fig. 6C). Lobe-

381 shaped bands of closely packed, linear-shaped blades parallel to one another and perpendicular to

382 the long axis of the bands, can be seen covering the left set of swimming flaps and the dorsal

383 surface of the body (sb, Figs. 2, 3). The blades change orientation along the length of the band,

384 as shown by the well-preserved organization on the fifth body segment (anteriormost structure

385 labelled 'sb' in Figs. 2, 3). Interpreted as bands of setal blades, these structures overlie the entire

386 width (tr.) of the bases of flaps five to nine on the right side. At the posterior left side of the

387 trunk, a small triangular structure, tentatively interpreted as a lateral flap, is apparently overlain

388 by a band of setal blades (fl? Fig. 3), but the organization of the different elements of the trunk is

389 obscured by their overlap in this area. An alternative interpretation would be that the band of

390 setal blades and putative flap belong to two distinct segments. The posteriormost preserved

391 structure is trapezoidal in outline and has a linear feature along its midline (lin, Figs. 2, 3). The

392 linear feature is most likely the centre of a folded band of setal blades. This indicates that the

393 body was disrupted in some way after deposition on the seafloor, in a process that also removed

394 any evidence of a tail fan, lobes, or spines (if present). Its small size compared to the other setal 
395 bands suggests that this may be the beginning of the taper at the posterior of the animal, or could

396 potentially represent the posteriormost set of setal blades.

397

398 Remarks. The new taxon displays a number of similarities to other hurdiids, for example in the

399 morphology of its mouthparts and body characters (Table 1). The unique combination of these

400 features, alongside the frontal appendage characters, warrant the erection of a new genus.

401

A tetraradial arrangement of the large plates, as observed in all other hurdiids where the

402 oral cone is well known (Cambroraster, Cordaticaris, Hurdia, Peytoia; Table 1) can be

403 tentatively proposed for Buccaspinea based on the locations of the large plates - whether these

404 locations are observed or deduced from the positions of the largest marginal teeth - on the sides

405 of the square-like central opening. The best-preserved large plate can be seen on the upper row

406 of plates in the counterpart (lp, Fig. 5) which is approximately at the centre of that row. As the

407 largest teeth are also found at the centre of the lower and right margins of the cone, these would

408 correspond to the position of the large plate on the upper row, and conform to a tetraradial

409 arrangement for this animal. The teeth in the oral cone of the new taxon are longer and broader

410 relative to the central opening and the size of the oral cone than in Hurdia, Peytoia, and to a

411 lesser extent Cordaticaris (Daley et al. 2013; Sun et al. 2020), resembling those of

412 Cambroraster (Moysiuk \& Caron, 2019). The plates of the oral cone in Cambroraster, the new

413 taxon, and possibly Cordaticaris bear multi-pointed teeth, which reduce in size from the midpoint 
414 of the side of the central opening towards the corners (Moysiuk \& Caron 2019, supplemental

415 figure 6A; Sun et al. 2020, fig. 6A, B).

416 The number of flap-bearing trunk segments (not including anterior reduced lamellae or

417 flaps known in Anomalocaris, Cambroraster, Hurdia and Lyrarapax) described for this new

418 taxon (at least 11) is towards the upper end of what is known in hurdiids (e.g. 11 in Aegirocassis

419 and Peytoia, eight in Cambroraster, six to nine in Hurdia victoria), with only Anomalocaris

420 canadensis (13) reported as having more among radiodonts (Whittington \& Briggs, 1985; Daley

421 et al. 2009, 2013; Daley \& Edgecombe, 2014; Van Roy et al. 2015; Moysiuk \& Caron, 2019).

422 The anterior three and posteriormost segments appear to be slightly narrower (tr.) compared to

423 most of the body, but otherwise body segments are of a similar size, as inferred from the relative

424 sizes of the flaps and setal structures. This suggests an approximately oblong outline for the

425 body, similar to what is known in Aegirocassis and Hurdia, and contrasting with the diamond

426 shape and significant posterior taper of Cambroraster and Peytoia. It is difficult to draw too

427 many similarities in the organisation of the setal structures with other radiodonts, owing to the

428 slight disarticulation of these features in BPM 1108. Setal structures splay over the dorsal surface

429 and the left side and appear to be dorsal to the triangular swimming flaps. It cannot be

430 determined if Buccaspinea has the one-dorsal-block arrangement of Aegirocassis, Cordaticaris

431 and Peytoia (Whittington \& Briggs, 1985; Van Roy et al. 2015; Sun et al. 2020), or the

432 alternative arrangement of two separate parallel lateral setal bands known in Hurdia (Daley et al.

433 2013). The lateral triangular flaps exhibit transverse lines across the whole width as in

Peer] reviewing PDF | (2020:08:52266:2:0:NEW 11 Nov 2020) 
434 Aegirocassis, Cambroraster, and Hurdia, although the flaps in Buccaspinea are broader than the

435 flaps of these three hurdiids.

436

The organization of the frontal appendages in Buccaspinea bears many similarities to

437

what is known for other members of Hurdiidae. Most hurdiid frontal appendages consist of a

438 region formed by five or six podomeres that bear plate-like endites, followed by a distal region in

439 which the podomeres have shorter, often spiniform, endites, or no endites at all. In hurdiids with

440 six plate-like endites (e.g. Hurdia, Stanleycaris and a taxon in open nomenclature - ?Peytoia

441 from the Tulip Beds), the proximal-most is often morphologically distinct from the remaining

442 ones and has been interpreted as belonging to the shaft region (Pates et al. 2019a). The exact

443 morphology of the most proximal of the six endites in this new taxon cannot be determined, but

444 under this hypothesis it would belong to the shaft region, and the remaining five plate-like

445 endites to the distal articulated region. If so, the appendages of this new animal would possess at

446 least 11 podomeres in the distal articulated region, and at least three in the shaft. The recent

447 description of Cordaticaris, which exhibits at least eight plate-like endites, suggests that this

448 distinction between shaft and distal articulated region cannot be made on number of endites

449 alone (i.e. hurdiids can have more than five blade-like endites in the distal articulated region),

450 and that a morphological distinction between the shaft endite and endites in the distal articulated

451 region is required to confidently discriminate between these two parts of the appendage. As this

452 cannot be determined for Buccaspinea, an alternate interpretation would place all six plate-like

453 endites in the distal articulated region of 12 podomeres, distal to two shaft podomeres lacking 
454 endites. Regardless, the endites on the appendages of the new genus reduce slightly in length

455 from proximal to distal, a character that has also been observed in Hurdia, and they appear to

456 curve slightly towards the distal portion of the appendage, as seen in Cambroraster, Hurdia, and

457 Stanleycaris. The elongate nature of the plate-like endites in Buccaspinea, which are greater than

458 five times the height of the podomeres to which they attach, is also seen in the filter feeding

459 hurdiids Aegirocassis and Pahvantia, and to a lesser extent the eudemersal sediment sifter

460 Cambroraster, and rare specimens of Hurdia (Daley et al. 2013; Van Roy et al. 2015; Lerosey-

461 Aubril \& Pates, 2018; Moysiuk \& Caron, 2019). The robust and elongate auxiliary spines of

462 Buccaspinea bear most similarity to Cambroraster and Hurdia, and strongly differ from the fine

463 setae of filter feeding hurdiids. It cannot be determined whether these auxiliary spines have

464 hooked tips (see Moysiuk \& Caron, 2019), but their length relative to endite width is more

465 similar to Cambroraster (auxiliary spines of a given endite overlapping two or more endites

466 distally) than Hurdia. The (absolute) length of the longest auxiliary spines of Buccaspinea is

467 comparable to the maximum length reported from Hurdia in the Burgess Shale (6 mm Daley et

468 al. 2013), and to what is observed in published specimens of Cambroraster falcatus (ca. $8 \mathrm{~mm}$,

469 measured digitally from Moysiuk \& Caron, 2019, fig. 2a). The presence of shorter spiniform

470 endites lacking auxiliary spines in Buccaspinea (de, Figs. 4, 5) is shared with Cambroraster

471 falcatus (three), Hurdia victoria (one or two), and Stanleycaris hirpex (two). Ursulinacaris

472 grallae also has two distal podomeres bearing reduced spiniform endites, but the latter are paired

473 as are all endites in this taxon (Pates et al. 2019a). Most hurdiid frontal appendages terminate in 
474 a single or pair of short spines, the terminal spine(s), in which the tips are orientated either

475 dorsally (e.g. Hurdia) or ventrally (e.g. Peytoia nathorsti). One recently described miniature

476 appendage (ca. $2 \mathrm{~mm}$ in length) assigned to Hurdiidae from the Ordovician of Wales displays an

477 elongate straight terminal spine, the length of which is approximately a third of that of the

478 appendage (Pates et al. 2020). The terminal spine of this animal also displays a 'U' shaped kink

479 towards its distal end, in the same direction as, but a lower magnitude to, the spine in BPM 1108.

480 These similarities in length (relative to appendage) and shape support the interpretation of the

481 structure protruding from the distal end of the right appendage in Buccaspinea as a long terminal

482 spine. In addition, a single specimen of Caryosyntrips from the Burgess Shale displays an

483 elongated and apparently flexible projection - albeit thicker than what is observed in

484 Buccaspinea and the Welsh hurdiid - at its terminus (Daley \& Budd, 2010, text-fig 6). On the

485 other hand, algal and cyanobacterial filaments similar in size to this structure are visible around

486 the fossil or associated with prominent parts of it, and therefore a superimposition of a short

487 terminal spine and a single algal or cyanobacterial string cannot be ruled out.

Aubril et al., 2020a, fig. 3A. B) and two isolated appendage specimens from the Spence Shale

(Daley et al. 2013, fig. 24C, D; Pates et al. 2018a, fig. 2.3, 2.4) are tentatively assigned to

491 Buccaspinea. All three appendages display characteristics of the plate-like endites strongly

492 reminiscent of BPM 1108. The length and curvature of the endites, alongside the relative length

493 and width of auxiliary spines exceed what is generally observed in Hurdia, which is the animal 
494 with the most similar frontal appendages. However, all three of these specimens from older Utah

495 Lagerstätten apparently exhibit fewer than three spiniform endites in the distal region. If this

496 could be explained by the poor preservation and the orientation of the distal region in two of the

497 specimens from the Spence Shale (Daley et al. 2013, fig. 24C, D), there are not convincing

498 explanations for the fewer number of distal endites observed in the Wheeler specimen and at

499 least one specimen from the Spence Shale (Pates et al. 2018a, fig 2.3, 2.4), hence the only

500 tentative assignment to the new species. All these specimens possess a short terminal spine; if

501 future findings confirm that the terminal spine of Buccaspinea frontal appendages is truly

502 elongate, this would preclude these other isolated frontal appendage specimens from being

503 assigned to the new taxon.

504

505 Genus Pahvantia Robison \& Richards, 1981

506

507 Type species. Pahvantia hastata Robison \& Richards, 1981 from the Drumian Wheeler

508 Formation in the House Range of Utah.

509

510 Diagnosis. See Lerosey-Aubril \& Pates (2018).

511

512 Pahvantia hastata Robison \& Richards, 1981

513 Figure 7 [Figure 7nearby] 
515 New material. UMNH.IP6101, 6105, and 6694, complete or near-complete isolated central

516 cephalic carapace elements; precise origins of these specimens unknown, but associated labels

517 mention the Marjum Formation, which crops out in the House Range of western central Utah,

518 USA; exceptionally-preserved fossils have been recovered from the middle part (30-300 $\mathrm{m}$ from

519 base) of this formation only, which belongs to the Bolaspidella polymerid trilobite Zone and the

520 Ptychagnostus punctuosus agnostoid Zone, Drumian Stage, Miaolingian Series.

521

522 Description. The Marjum central carapace elements hardly differ morphologically from

523 previously illustrated Pahvantia hastata specimens, despite being more than four times larger

524 than some (lengths $>80 \mathrm{~mm}$, sag; UMNH.IP6105 measures $103 \mathrm{~mm}$; Pates et al. 2020b, Table

$525 S 2$ ). Yet, they allow the recognition of a few morphological details not previously noticed in the

526 taxon. These larger specimens have a slightly wider (tr.) nuchal region relative to the main

527 region of the element (ca. 10 percent increase of the nuchal region width/main region width

528 ratio), when compared to smaller specimens. In addition, UMNH-IP6101 displays two tiny

529 spines on the posterior margin of its left lateral extension (or 'lappet'; Fig. 7B, D). One of these

530 marginal spines is located where the line marking the boundary between the lateral extension and

531 the main region meets the margin (Fig. 7D). A restudy of previously published material revealed

532 that this inner marginal spine is preserved in at least four other specimens (KUMIP134187 and

533 134879, UMNH.IP6088 and 6093; Fig. 7E-G). In others, no discernible spine occurs, but the 
534 margin forms an angle at this point (e.g. KUMIP314089; Lerosey-Aubril \& Pates, 2018, fig. 1a,

535 b). A second marginal spine is located a short distance abaxially from the first. Its presence could

536 be confirmed in two previously published specimens (KUMIP134187 and 134879; Fig. 7E).

538 Remarks. This is the first report of the presence of Pahvantia hastata in the Marjum Formation,

539 this taxon being hitherto only known from the underlying Wheeler Formation in both the House

540 Range and the Drum Mountains (Robison \& Richards, 1981; Lerosey-Aubril \& Pates, 2018;

541 Lerosey-Aubril et al. 2020a). The new fossils represent the youngest occurrence of the species

542 and likely extend its biostratigraphical range to the P. punctuosus Zone.

The larger sizes of these specimens - UMNH.IP6105 is the biggest specimen of the

544 species yet discovered at $103 \mathrm{~mm}$ (sag.) - are not necessarily indicative of biological differences

545 between the Wheeler and Marjum assemblages, but may simply stem from a human bias (e.g.

546 preference for larger fossils of the collector). The slight increase of the width of the nuchal

547 region relative to the main region of the central carapace element is the only ontogenetic change

548 detectable in the 17 central carapace elements available for study. Otherwise, the Marjum

549 specimens are strikingly similar to previously described specimens, which confirms that the

550 morphology of this central part of the cephalic carapace was strongly constrained, possibly for

551 functional reasons (Lerosey-Aubril et al. 2020a).

552

The marginal spines are reminiscent to those projecting along the posterior margins of

553 the posterolateral extensions in Cambroraster falcatus (Moysiuk \& Caron, 2019, figs. 1a, b, $g, k$, 
554 sup. figs. $4 C, 5 D, 7 C$ ). As in $C$. falcatus, marginal spines seem to mark the abaxial limits of the

555 ocular notches, even if the notches in P. hastata are represented by concave portions of the

556 margin, rather than actual notches as in C. falcatus. Eyes on stalks originating within ocular

557 notches of hurdiid central elements have been described in Hurdia (Daley et al. 2009 fig. 1A, B;

558 Daley et al. 2013 fig. $3 A$, B), but no marginal spines were identified in this genus, neither in

559 published material, nor in specimens accessioned at the Museum of Comparative Zoology (Pates

560 et al. 2020b, Table S1). The lateral projections of the central element of putative radiodont

561 Zhenghecaris shankouensis also bear spines (one each) along their posterior margins, which

562 might be equivalent to those of the two North American taxa, though substantially more robust

563 (Zeng et al. 2018, fig. 14A, I). Lastly, Sun et al. (2020) recently described marginal spines in

564 Cordaticaris that are similar in number (two per side), location (immediately abaxial to ocular

565 notch), and size (tiny compared to sclerite size) to those of Pahvantia, and acknowledged the

566 presence of marginal spines in the latter taxon. These spines represent one of several features of

567 the central carapace element shared by the two taxa (e.g. main region displaying linear pattern,

568 extending into a short anterior spine, and particularly well-differentiated from lateral regions),

569 which suggest a close phylogenetic relationship between them.

571 Family uncertain

572 Genus Caryosyntrips Daley \& Budd, 2010 
574 Type species. Caryosyntrips serratus Daley \& Budd, 2010, from the Wuliuan Burgess Shale,

575 British Columbia, Canada.

576

577 Diagnosis. See Pates \& Daley (2017).

578

579

Caryosyntrips camurus

580

Figures 8, 9 [Figure 8 nearby]

581

582

Material, locality, horizon. The material consists of two isolated frontal appendages preserved as

583

lateral compressions. Specimen BPM1100, only tentatively assigned to the species, was collected

584

in the Drumian strata (Ptychagnostus punctuosus Biozone) of the middle Marjum Formation at

585 the 'Red Wash' locality (locality 716 of Robison \& Babcock, 2011; GPS: $39.318275^{\circ}$, -

$\left.586113.272793^{\circ}\right)$, House Range, Millard County, Utah. Specimen UMNH.IP 6122 (a, b) was found

587 in the Marjum Formation, and therefore in the House Range of western central Utah, USA,

588 although its exact origins are unknown.

589

590 Description. BPM1 100 (Fig. 8) is an isolated frontal appendage that measures ca. $33 \mathrm{~mm}$ along

591 the dorsal margin. This specimen is composed of a bell-shaped proximal region (Fig. 8), a

592 rectangular intermediate region (ca. $10 \mathrm{~mm}$ along dorsal margin), and a trapezoidal distal region

593 (ca. $16 \mathrm{~mm}$ along dorsal margin). The proximal region is separated from the rectangular 
594 intermediate region by an arcuate boundary (hatched line in Fig. 8B), marking the presence of a

595 second layer of cuticle distally. The dorsal and ventral margins are separated by ca. $4 \mathrm{~mm}$ in the

596 rectangular region. A change in slope on the dorsal margin marks the boundary between the

597 proximal and intermediate regions. In the intermediate region the appendage tapers distally at an

598 angle of $12-13^{\circ}$ between dorsal and ventral margins until it reaches half of its proximal height at

599 its obliquely truncated tip. A dark coloured band runs at mid-height of the intermediate and distal

600 regions, and the dorsal margin of this band continues as a line that curves ventrally in the

601 proximal region. Ventral to this band are numerous lines running dorso-ventrally, many of which

602 look like proximal extensions of the endites. Some of these structures likely represent the second

603 row of endites, which have been displaced slightly owing to the rotation of the appendage,

604 whereas others may represent incomplete endites or poorly preserved podomere boundaries.

605 Straight endites, which curve slightly towards the proximal part of the appendage at their distal

606 tips, are closely spaced and attach separately to the ventral portion of the appendage (en, Fig. 8).

607 These endites are of variable length (1.5 to at least $4 \mathrm{~mm})$ and width $(0.4$ to at least $1.2 \mathrm{~mm})$. The

608 rotation of the appendage cannot account for this variation, as two endites that form a pair (Fig.

609 8) are of a similar width to one another, despite one being in a deeper plane owing to the rotation

610 of the appendage. These endites are substantially slenderer than the largest and widest endites

611 visible on the appendage.

612 A $2.5 \mathrm{~mm}$ wide structure at the proximal margin of the ventral surface could represent

613 the broken base of an especially large endite, but this structure has a different texture to the other 
614 endites. This putative endite could have lost the outer layer of cuticle, or it may simply represent

615 some associated organic matter in the matrix slightly overlain by the Caryosyntrips appendage.

616 Similar associated organic matter is abundant in this specimen, with a similar sized block

617 overlying and obscuring some of the endites. The appendage appears smooth and essentially

618 featureless dorsal to the dark colored band. Faint lines running proximo-ventrally from indents of

619 the dorsal margin are interpreted as weakly-expressed podomere boundaries, and four

620 protrusions from the dorsal surface can be seen (ds, Fig. 8). These protrusions could represent

621 poorly preserved dorsal spines, but are more likely additional associated organic fragments,

622 unrelated to the Caryosyntrips appendage.

623

The second specimen, UMNH.IP 6122 (Fig. 9), is an incomplete isolated frontal

624 appendage, which measures ca. $86 \mathrm{~mm}$ along the dorsal margin. The specimen is missing the

625 proximal region and parts of the dorsal region. The rectangular intermediate region is bounded

626 proximally by an S-shaped margin, is ca. $17 \mathrm{~mm}$ wide (perpendicular distance between dotted

627 lines delineating intermediate region in Fig. 9B) and $20 \mathrm{~mm}$ tall (Fig. 9). The trapezoidal distal

628 region measures $69 \mathrm{~mm}$ along the dorsal surface, and tapers at an angle of ca. $12^{\circ}$ between its

629 dorsal and ventral margins until reaching $3 \mathrm{~mm}$ in height at its blunt termination. Faint

630 boundaries separating at least 12 podomeres can be discerned mostly in the dorsal region.

631 Closely spaced endites curve towards the proximal region of the appendage, and vary slightly in

632 length and width (maximum length and width measured are $2 \mathrm{~mm}$ and $0.8 \mathrm{~mm}$ respectively; en,

633 Fig. 9). At least four projections form the dorsal margin are visible, which potentially represent 
634 dorsal spines (ds?, Fig. 9). As these structures are not consistent in terms of their morphology

635 (the proximal-most one is straight, but more distal projections are curved), and abundant organic

636 matter of a similar shape and preservation permeates the matrix, these structures are best

637 interpreted as unrelated to the appendage. Large patches of cuticular material associated with the

638 proximal region, but distinct from it, potentially represent a poorly preserved second appendage

639 (ap2?, Fig. 9).

640

641 Remarks. These two specimens are assigned to the genus Caryosyntrips based on the presence of

642 a subtriangular outline (when flattened), triangular endites, and incomplete podomere

643 boundaries. These two Caryosyntrips, the first reported from the Marjum Formation (Drumian),

644 also represent the youngest occurrence of this genus. Three Caryosyntrips species were

645 previously reported from older Miaolingian deposits in Laurentia: C. camurus (Spence Shale and

646 Burgess Shale, Wuliuan; Pates \& Daley, 2017), C. durus (Wheeler Formation, Drum Mountains;

647 Drumian; Pates \& Daley, 2017), and C. serratus (Burgess Shale and Wheeler Formation, House

648 Range; Daley \& Budd, 2010; Pates \& Daley, 2017). The oldest (and largest) member of the

649 genus (Caryosyntrips cf. C. camurus) is the only known specimen currently described from

650 outside Laurentia (Gondwana, Valdemiedes Formation, Cambrian Stage 4; Pates \& Daley, 2017)

651 although the affinities of this specimen have been contested (Gámez Vintaned \& Zhuravlev,

652 2018; Pates et al. 2018b).

Peer] reviewing PDF | (2020:08:52266:2:0:NEW 11 Nov 2020) 
654 dorsal margins, orientation of endites, and subtle differences in the outline of the appendage

655 (Pates \& Daley, 2017). The type species, C. serratus, bears a row of closely spaced small spines

656 along the dorsal margin, has distally orientated endites, and has a slightly curved dorsal margin.

657 This contrasts with $C$. camurus, which lacks dorsal spines completely, possesses endites which

658 project closer to perpendicular to the ventral margin (except in one specimen from the Spence

659 Shale; Pates \& Daley, 2017, fig. 4C), and terminates in three podomeres of a very reduced

660 height. The third species, C. durus, bears small spines all along its dorsal margin in addition to

661 one large spine per podomere, and endites close to perpendicular to the ventral margin; the entire

662 appendage is triangular in outline, no subrectangular region being differentiated proximally

663 (Pates \& Daley, 2017). Appendages of Caryosyntrips also display a notable amount of

664 intraspecific variation in general outline and endite pattern (shape, position, size, and number)

665 depending on the quality of preservation and orientation of the material, which may considerably

666 complicate assignment to a given species.

667

The two specimens described here differ in the size, morphology, and spacing of the

668 endites, and the presence/absence of a medial band. The proximal region of Caryosyntrips

669 appendages typically display a convex to bell-shaped outline, as observed in BPM 1100 (Daley

$670 \&$ Budd, 2010, text-fig. 5A; Pates \& Daley, 2017, figs. 3A, C-F). A concave or sigmoidal

671 proximal margin similar to that of UMNH.IP 6122 has been observed in some Caryosyntrips

672 specimens (e.g. Pates \& Daley, 2017, fig. 3B), where the proximal part of the appendage may 
673 have broken off along or close to the boundary between two podomeres. Endites projecting

674 approximately perpendicular to the ventral margin as observed in BPM 1100 are known in some

675 specimens of $C$. camurus and $C$. durus, however the substantial size variation of endites is not

676 known in other members of the genus (ratio of endite to appendage is 1:9 in BPM 1100,

677 compared to 1:12 in C. camurus; Pates \& Daley, 2017, fig. 4B, appendix). The endite

678 morphology of UMNH.IP 6122 is most similar to what is seen in the holotype for C. camurus

679 (Pates \& Daley 2017, fig. 4A). The observation of a medial band running through most of the

680 appendage is another distinctive trait of BPM 1100. A comparable feature occurs in a single

681 previously illustrated specimen of C. serratus (Pates \& Daley 2017, fig. 3F) but is unknown in

682 any C. camurus. A distinction between the ventral portion, with well-expressed podomere

683 boundaries, and an apparently unsegmented dorsal portion is also clearly expressed in the

684 holotype of the same species, but this specimen lacks a clear medial band (Pates \& Daley 2017,

685 fig. 3A).

686

Specimen UMNH.IP 6122 can be confidently assigned to Caryosyntrips camurus,

687 assuming that the dorsal projections are taphonomic in origin and do not represent poorly

688 preserved dorsal spines. The shape of the appendage, as well as the size, morphology, and

689 spacing of the endites, all fall within the range of what is known for other members of this

690 species (Pates \& Daley, 2017). The morphology of the endites is distinct from the only other

691 member of the species from Utah, a partial specimen from the Spence Shale, which displays

692 straight endites with a rounded distal tip (Pates \& Daley, 2017). 
694 projections are taphonomic in origin, the lack of dorsal spines with two rows of simple endites

695 fits with the current diagnosis of $C$. camurus. Whereas the endites of BPM 1100 are larger

696 relative to appendage length than any other member of the species (and genus), this would only

697 require a slight increase in the known morphological variation of spine length within the taxon to

698 accommodate this specimen. However, the unequal spacing of paired endites, and their variation

699 in size, along the ventral margin of the appendage are not observed in any C. camurus specimen.

700 These characters (spacing and size variation in endites) may warrant the erection of a new

701 Caryosyntrips species in the future, but meanwhile we tentatively assign BPM 1100 to $C$.

702 camurus.

703

All known species of Caryosyntrips are known from Utah Lagerstätten: C. camurus in

704 the Spence Shale and Marjum Formation, C. durus in the Wheeler strata of the Drum Mountains,

705 C. serratus in the Wheeler strata of the House Range), and a potentially novel Caryosyntrips

706 species in the Marjum Formation (Daley \& Budd 2010; Pates \& Daley, 2017; Lerosey-Aubril et

707 al 2020a; this study).

708

709 Discussion

710 Ecological diversity of the Marjum radiodont fauna

711 The fossils described herein quadruple the known radiodont diversity in the Marjum fauna,

712 adding the taxa Buccaspinea, Caryosyntrips, and Pahvantia to the previously known Peytoia. 
713 Interestingly, the four Marjum taxa significantly differ from each other in both body and frontal

714 appendage morphologies, which suggests that if they inhabited the waters of the House Range

715 Embayment at the same time, they were probably not ecological competitors (Daley \& Budd,

716 2010). Pahvantia hastata was recently shown to possess frontal appendages with numerous

717 densely packed setae, structures consistent with suspension feeding habits (Lerosey-Aubril \&

718 Pates, 2018). Added to an elongate cephalic carapace, this appendicular morphology suggests

719 that $P$. hastata might have inhabited the uppermost layer of the water column, where it fed on

720 micro- to mesoplankton.

721 Caryosyntrips is the least well-known representative of the group - only a partial

722 carapace element is known of its non-appendicular anatomy to date (Daley \& Budd 2010). The

723 characteristics of the frontal appendages in this genus, such as their subtriangular outline and

724 incomplete podomere articulations, are so unique among radiodonts that this taxon is typically

725 recovered outside a monophyletic Radiodonta in phylogenetic analyses (Vinther et al. 2014;

726 Cong et al. 2014; Van Roy et al. 2015; Liu et al. 2018; Lerosey-Aubril \& Pates, 2018; Moysiuk

$727 \&$ Caron 2019). Caryosyntrips is considered as a free swimmer, similar to other radiodonts and

728 closely related taxa, although its body morphology is unknown and so the extent of its swimming

729 abilities and whether it lived close to the seafloor or high in the water column cannot be

730 determined. It has been speculated that the frontal appendages of Caryosyntrips may have

731 worked in a coordinated occlusive motion, with the two appendages moving towards one another

732 to grasp or slice food (Daley \& Budd, 2010; Pates et al. 2017). The size of these appendages (2- 
$73320 \mathrm{~cm}$ in length; Pates \& Daley, 2017) and their peculiar inferred function among radiodonts

734 (operating as a pair) both suggest that adult individuals of Caryosyntrips may have fed on much

735 larger items than the micro- to meso-planktonic organisms ingested by Pahvantia hastata.

736 The frontal appendages of Buccaspinea bear plate-like endites with extremely robust

737 auxiliary spines, whereas its large oral cone is equipped with particularly robust marginal teeth.

738 The overlap of endites with auxiliary spines would have prevented the capture of prey between

739 endites, and so it is inferred that this animal would have used these endites for sweep feeding, as

740 has been suggested for Cambroraster and Hurdia which have a comparable frontal appendage

741 organization (Daley et al. 2013; Moysiuk \& Caron, 2019). The large size of the oral cone and

742 robust spines surrounding a square opening strongly suggest that this was used in combination

743 with the appendages for capture and breakdown of prey items, although the exact manner in

744 which the radiodont oral cone functioned is still poorly understood (e.g. Whittington \& Briggs

745 1985; Hagadorn et al., 2010; Daley \& Bergström 2012).

The diamond-shaped body of Peytoia, with two rows of sub-equal swimming flaps

747 rather long ventral flaps and more reduced dorsal ones (Whittington \& Briggs 1985; Daley et al.

748 2013; Van Roy et al. 2015; Fig. 10C) probably conferred significant swimming power, similar to

749 amplectobeluids and anomalocaridids. The presence of dorsal flaps for steering - and potentially

750 also stability in the water column - in Peytoia and other hurdiids (Van Roy et al. 2015), rather

751 than a tail fan and/or caudal rami, suggests reduced agility for this animal when compared to 
752 Anomalocaris and Amplectobelua, whereas the different frontal appendage morphologies of

753 these taxa imply distinct prey handling methods (Daley \& Budd, 2010).

In summary, the exact autecology of the Marjum radiodonts remains incompletely

755

understood, but there is some evidence that if these taxa truly lived together at a given time, they

756

occupied distinct ecological niches. The positions in the water column that these organisms

757

occupied, their swimming abilities, their sizes at maturity, their feeding mechanics, and the size

758

and origin of the food items they ingested are all factors potentially explaining how these

759

closely-related taxa might have co-occurred in the same ecosystem. This is similar to the

760

ecological structuring at other Cambrian localities where multiple radiodonts are present, notably

761

at the Burgess Shale where up to seven or more radiodont species have been found at the same

762 site, each interpreted to employ a different feeding strategy, presumably to reduce competition

763 (Daley \& Budd 2010).

Comparison of the Cambrian radiodont faunas from western Utah

766 The occurrence of four Konservat-Lagerstätten within the Cambrian deposits of the House Range

767 Embayment provides a rare opportunity to study the distribution of different radiodont taxa in

768 both space and time (over ca. 5 million years). Despite the small sample sizes, which are a result

769 of the rare nature of exceptional preservation and significant collecting effort required to obtain

770 radiodont material from these deposits, a comparison of the radiodont faunas of these

771 assemblages (summarized in Table 2) reveals both geographic and temporal signals. Differences 
772 are not considered taphonomic in origin as sedimentological studies have demonstrated a similar

773 palaeoenvironmental setting for the Wheeler, Marjum and Weeks Konservat-Lagerstätten in the

774 House Range (Gaines \& Droser, 2005, 2010; Gaines et al. 2005; Lerosey-Aubril et al. 2018). In

775 addition, comparable biostratinomic and geochemical contexts have been reconstructed for the

776 intervals hosting exceptional preservation within the Wheeler and Marjum formations (Gaines \&

777 Droser 2010). The only notable taphonomic difference between these deposits is the late

778 diagenetic metamorphism that has affected the Weeks Formation, resulting in a different

779 appearance of the soft-bodied fossils recovered from those beds.

780 The lower Drumian Wheeler biota from the House Range (Wheeler-HR) is most

781 diverse, exemplifying the correlation between taxonomic richness and varied ecological niches

782 within a radiodont assemblage. Taxa with particularly distinctive morphologies are found here

783 (Lerosey-Aubril et al. 2020a; Pates et al. 2017), in addition to all the forms described in the

784 Marjum Formation. An almost complete body specimen of Anomalocaris was reported from this

785 locality by Briggs et al. (2008), but restudy suggests that it cannot be accommodated within the

786 type-genus of the family Anomalocarididae (work in progress).

787

The coeval Wheeler Formation in the Drum Mountains (Wheeler-DM) differs in both

788

species richness and taxonomic composition (Table 2), sharing only Pahvantia hastata with the

789

Wheeler-HR fauna. This may support interpretation of Pahvantia as a free swimmer

790

predominantly inhabiting the euphotic zone (Lerosey-Aubril et al. 2018), or could simply result

791 from its greater abundance and therefore greater chance of being found, as suggested by the 
792 numerous carapace elements recovered in the Wheeler-HR (Lerosey-Aubril et al. 2020a). We

793 include an isolated appendage illustrated by Halgedahl et al. (2009, fig. 10L) in our tally of

794 radiodonts from Wheeler-DM, with its unique combination of features (e.g. tall podomeres, stout

795 spiniform endites alternating in length) likely representing a new anomalocaridid genus. The

796 different compositions of the two Wheeler radiodont assemblages confirm the view that distinct

797 biotas are preserved in the Wheeler strata of the House Range and the Drum Mountains

798 (Robison, 1991; Robison et al. 2015; Lerosey-Aubril \& Skabelund, 2018; Lerosey-Aubril et al.

799 2020a). However, the Wheeler-DM has to date yielded only four radiodont fossils, and

800 additional discoveries could still significantly change the compositions of the Wheeler radiodont

801 faunas.

802 The present contribution significantly increases the known diversity of the Marjum

803 radiodont fauna. Although less species rich, this 'middle' Drumian assemblage is strikingly

804 similar to the slightly older ('lower Drumian') Wheeler-HR radiodont fauna (Table 2).

805 Pahvantia, Peytoia and possibly Buccaspinea are represented by the same species in the

806 Wheeler-HR and the Marjum biotas, whereas distinct species of Caryosyntrips occur in these

807 two assemblages and the Wheeler-DM. As to the broader palaeobiogeography of these taxa,

808 Pahvantia is endemic to western Utah (Lerosey-Aubril et al. 2020a) and Buccaspinea to Utah as

809 whole (this study), whereas the Laurentian species of Peytoia also occurs in the Wuliuan Spence

810 Shale in northern Utah (e.g. Pates et al. 2018a) and the Wuliuan Burgess Shale of British

811 Columbia (e.g. Daley et al. 2013). While Caryosyntrips durus has a paleobiogeographic range 
812 limited to the Wheeler-DM, C. serratus and C. camurus are known in both Utah (Wheeler-HR,

813 and Marjum and Spence Shale, respectively) and British Columbia (Burgess Shale) (Pates \&

814 Daley, 2017). The complexity of these stratigraphical and palaeogeographical distribution

815 patterns, even locally, suggests notable biological and/or ecological differences between

816 radiodont taxa.

817 Notably, none of the 10 radiodont species recovered from the Wheeler and Marjum

818 Formations has yet been found in the youngest of the Cambrian Lagerstätten of western Utah, the

819 Weeks Formation (Table 2). These Guzhangian strata have yielded two species that are

820 confidently assigned to Anomalocaris, even if neither has yet been formally described (Lerosey-

821 Aubril et al. 2014). Examination of over 800 specimens collected more recently confirms the

822 presence of two taxa, their assignment to Anomalocaris, and the small size of the individuals

823 inhabiting the House Range Embayment at that time (Lerosey-Aubril et al. 2014). This genus is

824 otherwise known from older deposits regionally, in the Cambrian Stage 4 Pioche Formation in

825 eastern Nevada (Lieberman, 2003; Pates et al. 2019b) and the Spence Shale in northern Utah

826 (Briggs et al. 2008). As discussed above, the presence of this genus in the Wheeler-HR is

827 doubtful (contra Briggs et al. 2008) and therefore, the Weeks specimens are the only fossils

828 confidently assigned to Anomalocaris in the Cambrian of western Utah. The absence of hurdiids

829 in the Weeks assemblage is also particularly striking (Table 2), for they are the most common

830 components of the other Miaolingian radiodont faunas of Utah (including the Spence fauna).

831 Thus, radiodonts confirm the singular composition of the Weeks exceptionally-preserved fauna, 
832 a uniqueness that was interpreted as evidence for an important biotic turnover around the

833 Drumian/Guzhangian boundary, at least regionally (Lerosey-Aubril et al. 2018).

834

835 The Marjum fauna and its pelagic components

836 The Marjum Formation has yielded 143 species (Robison et al. 2015), but this whole unit is

837 particularly thick (ca. $430 \mathrm{~m}$ ) and spans three agnostoid biozones (Ptychagnostus atavus, $P$.

838 punctuosus, Lejopyge laevigata; Robison \& Babcock, 2011). Exceptional preservation is

839 confined to the lower part of the P. punctuosus Zone only (ca. 30 to $300 \mathrm{~m}$ from base; Robison

840 pers. com. 2019), which allows the presently known diversity of this remarkable biota to be

841 quantified at 102 species (82 genera), amongst which 97 (77 genera) represent animals (Pates et

842 al. 2020b, Supplementary Data 3). Despite this adjustment for stratigraphic position, the Marjum

843 fauna remains the most diverse of the three exceptionally-preserved Miaolingian assemblages of

844 the House Range (HR), those of the Wheeler (Ptychagnostus atavus biozone) and Weeks

845 (Proagnostus bulbus biozone) Formations totalling 77 and 81 species, respectively. It also differs

846 from these latter two formations by the noticeably greater proportion of pelagic components (Fig.

$84710 \mathrm{~A}-\mathrm{F})-36 \%$ of the generic diversity, against $32 \%$ in the Wheeler (HR) and $17 \%$ in the Weeks

848 - a pattern reinforced by the new radiodont occurrences reported herein. This richness in pelagic

849 taxa (see definition above) results in part from a greater diversity of agnostoids (Fig. 10A),

850 which comprise no less than 23 species (14 genera). These small euarthropods, considered herein

851 as forming a clade distinct from trilobites (Bergström \& Hou 2005; Haug et al. 2010; Edgecombe 
852 \& Legg 2013), account for $18 \%$ of the total generic diversity of the Marjum exceptional fauna,

853 which is twice than what they account for in the Wheeler (HR) and the Weeks faunas. There are

854 slightly more agnostoid genera than trilobite genera in the middle Marjum assemblage, whereas

855 the diversity of trilobites is more than twice that of agnostoids in the other two faunas. The

856 Marjum remarkable fauna is also unique in featuring animals that are extremely rare in Cambrian

857 marine assemblages: jellyfish (Bonino, 2019). Marjum medusiform fossils (Fig. 10B) were

858 described by Cartwright et al. (2007), who interpreted them as the oldest medusoid

859 representatives of three classes of cnidarians (i.e. Cubozoa, Hydrozoa, and Scyphozoa). Other

860 pelagic components include more common taxa, such as radiodonts - previously only known by

861 the sole genus Peytoia (Fig. 10C; Briggs \& Robison, 1984; Pates et al. 2018a) - and the

862 'bivalved arthropods' Branchiocaris, Perspicaris, and Tuzoia (Fig. 10D-F; Robison \& Richards,

863 1981; Briggs \& Robison, 1984).

864 Interpreting this greater diversity of pelagic components, especially agnostoids, in

865 relation to palaeoenvironmental setting is challenging. Cambrian agnostoids tend to be associated

866 with distal shelf to slope biofacies in low- and mid-latitude regions (e.g. Robison, 1976;

867 Sundberg, 1991; Pegel, 2000; Peng et al., 2012; Hally \& Paterson, 2014; Babcock et al. 2015,

868 2017), and many taxa have extensive palaeogeographical ranges allowing their use for

869 intercontinental correlation (Robison 1976; Peng \& Robison, 2000; Peng et al. 2012; Álvaro et

870 al. 2013; Babcock et al. 2015, 2017). Whether agnostoids are interpreted as epibenthic (see

871 definition above) or pelagic organisms (Esteve \& Zamora, 2014 and references therein), the 
872 doubling of their specific diversity between the upper Wheeler strata and those of the middle

873 Marjum suggests a deepening of the environment. This observation may appear hard to reconcile

874 with the traditional depiction of a relatively continuous filling of the House Range Embayment

875 through deposition of the Wheeler, Marjum, and Weeks Formations (Miller et al. 2012). This

876 general picture is supported by sequence stratigraphy regionally, which shows that the Marjum

877 Formation records variations of sea levels in the forms of third to fifth order cycles, but overall

878 the evolution of the lithofacies up stratigraphy indicates a general shallowing of the depositional

879 environment (Smith, 2007). This shallowing trend is materialized by the southward progradation

880 of shallow platform facies down the carbonate ramp forming the northern margin of the basin

881 (Rees, 1986; Miller et al. 2012). However, sediment accumulation greatly varied within the

882 basin, which was not filled everywhere at the same rate and the same time. Importantly, Rees

883 (1986) noted that for most of the existence of the embayment, the low rate of sedimentation in its

884 axial part (e.g. Marjum Pass area) was not sufficient to overcome subsidence, unlike the situation

885 along its northern flank. The inferred relative depth of the central part of the basin somewhat

886 increased during the deposition of the lower (0-200 m) Marjum Formation according to regional

887 sequence stratigraphy (Smith, 2007, fig. 30). In other words, while some parts of the basin were

888 being filled, others remained as deep as before or even deepened. Considering that many Marjum

889 localities, including the main sites yielding non-biomineralized fossils (i.e. the Sponge Gully and

890 White Hill localities), correspond to this stratigraphic interval (ca. 30-200 $\mathrm{m}$ from base) and

891 geographic area (Marjum Pass and nearby), the observed increase of agnostoid diversity could 
892 indeed be interpreted as supporting evidence for a decoupled bathymetric evolution between the

893 axial and marginal parts of the basin. An alternative, or possibly complementary explanation is

894 that the circulation of water in and out of the embayment changed during the Drumian (e.g.

895 stronger landward currents), allowing enhanced faunistic influences of the oceanic province.

896

897 Conclusions

898 The discovery of new material from the Marjum Formation continues to highlight the diversity

899 of Utah Konservat-Lagerstätten, and the description of the new taxon Buccaspinea cooperi,

900 known only from Utah deposits, further demonstrates the importance of taking a global approach

901 to our understanding of early animal life. The youngest occurrences of two radiodont genera,

902 Caryosyntrips and Pahvantia, are also reported from the Drumian Marjum Formation in Utah,

903 which brings a total radiodont diversity of this unit to four taxa, the presence of the youngest

904 Peytoia nathorsti in these strata being already well established (Briggs \& Robison, 1984; Pates

905 et al. 2018a). These radiodont taxa are all known from the younger Wheeler Formation in the

906 House Range, but contrast with the radiodonts of the younger Weeks Formation (Guzhangian),

907 providing further support for a Guzhangian faunal restructuring, at least regionally. These four

908 radiodonts are interpreted as nektonic, and their discovery further documents the relatively high

909 diversity of pelagic animals in the Marjum Formation, in contrast to the other Lagerstätten of the

910 House Range. This may be the result of a slight deepening of this part of the basin during the

911 Drumian, and/or changing ocean circulation at this time bringing in additional pelagic taxa. 
912

\section{Acknowledgements}

914 Richard A. Robison generously provided us with critical data on the stratigraphic positions of the

915 Marjum excavation sites and their fossil assemblages they yield. Carolyn Levitt-Bussian and

916 Randal B. Irmis kindly assisted us during our visits to the Natural History Museum of Utah

917 (UMNH) and facilitated the study of the specimens housed in this institution. These specimens

918 were deposited by the Bureau of Land Management, and we particularly thank Scott E. Foss and

919 Greg McDonald, who also provided curatorial assistance. Manuele Bianchi assisted with the loan

920 of BPM 1108 from the Back to the Past Museum to the University of Lausanne. Peter O.

921 Baumgartner (University of Lausanne) permitted the use of their photography equipment at the

922 University of Lausanne. Early drafts of work by paleoartist Holly Sullivan

923 (www.sulscientific.com) helped us to picture how this ecosystem may have looked. Julien

924 Kimmig kindly provided the pictures of KUMIP153917a (Tuzoia) and KUMIP2047971a

925 (Branchiocaris) illustrated in Figure 10D and F, respectively. Bruce S. Lieberman and Julien

926 Kimmig (KUMIP), and Jessica Cundiff and Mark Renczkowski (MCZ), facilitated study of

927 comparative material. The manuscript benefitted from the fruitful comments of L. Babcock, R.

928 LaVine, and an anonymous referee. We would like to express our sincere gratitude to all of these

929 people for their invaluable help before and during the course of our study.

930

931 References 
932 Aitken, J.D. 1997. Stratigraphy of the Middle Cambrian platformal succession, southern Rocky

933 Mountains. Bulletin of the Geological Survey of Canada 398, 1-322.

934 Álvaro, J. J., Ahlberg, P., Babcock, L. E., Bordonaro, O. L., Choi, D. K., Cooper, R. A.,

935 Ergaliev, G. K. H., Gapp, I. W., Ghobadi Pour, M., Hughes, N. C., Jago, J. B., Korovnikov, I.,

936 Laurie, J. R., Lieberman, B. S., Paterson, J. R., Pegel, T. V., Popov, L. E., Rushton, A. W. A.,

937 Sukhov, S. S., Tortello, M. F., Zhou, Z. and Żylińska, A. 2013. Global Cambrian trilobite

938 palaeobiogeography assessed using parsimony analysis of endemicity. Geological Society,

939 London, Memoirs 38, 273-296.

940 Babcock, L. E., Peng, S. C., Brett, C. E., Zhu, M. Y., Ahlberg, P., Bevis, M. and Robison, R. A.

941 2015. Global climate, sea level cycles, and biotic events in the Cambrian Period. Palaeoworld

$942 \quad 24,5-15$.

943 Babcock, L. E., Peng, S. and Ahlberg, P. 2017. Cambrian trilobite biostratigraphy and its role in

944 developing an integrated history of the Earth system. Lethaia 50, 381-399.

945

Doi:10.1111/let.12200.

946 Bergström, J. and Hou, X.-G. 2005. Early Palaeozoic non-lamellipedian arthropods. 73-93. In

947 Koenemann, S. and Jenner, R. A. (eds). Crustacean issues 16: Crustacea and Arthropod

948 Relationships. Taylor and Francis, Boca Raton, FL.

949 Bonino, E. 2019. Spiagge Cambriane - Meduse e tappeti algali. Back to the Past Museum,

$950 \quad$ Cancun, $232 \mathrm{pp}$. 
951 Bonino, E. \& C. Kier. 2010. The Back to the Past Museum Guide to Trilobites. Casa Editrice

952 Marna, Lecco, 494 pp.

953 Briggs, D. E. G. and Robison, R. A. 1984. Exceptionally preserved non-trilobite arthropods and

954 Anomalocaris from the Middle Cambrian of Utah. The University of Kansas

955 Paleontological Contributions, Paper 111, 1-24.

956 Briggs, D. E. G., Lieberman, B. S., Hendricks, J. R., Halgedahl, S. L. and Jarrard, R. D. 2008.

957 Middle Cambrian arthropods from Utah. Journal of Paleontology 82, 238-254.

958 Budd, G. E. 1998. Stem group arthropods from the Lower Cambrian Sirius Passet fauna of north

959 Greenland. In Arthropod relationships, 125-138. Springer, Dordrecht.

960 Budd, G. E. and Jensen, S. 2000. A critical reappraisal of the fossil record of the bilaterian phyla.

$961 \quad$ Biological Reviews 75, 253-295.

962 Butterfield, N. J. 2011. Animals and the invention of the Phanerozoic Earth system. Trends in

963 Ecology and Evolution 26, 81-87.

964 Butterfield, N. J. 2018. Oxygen, animals and aquatic bioturbation: an updated account.

965 Geobiology 16, 3-16.

966 Caron, J.-B. and Jackson, D. A. 2008. Paleoecology of the greater phyllopod bed community,

967 Burgess Shale. Palaeogeography, Palaeoclimatology, Palaeoecology 258, 222-256.

968 Caron, J.-B. and Rudkin, D. M. 2009. A Burgess Shale Primer: History, Geology, and Research

969 Highlights. Field Trip Companion Volume, ICCE 2009. Burgess Shale Consortium,

$970 \quad$ Toronto, $108 \mathrm{pp}$. 
971 Caron, J.-B., Conway Morris, S. and Cameron, C. B. 2013. Tubicolous enteropneusts from the $972 \quad$ Cambrian period. Nature 495, 503-506.

973 Cartwright, P., Halgedahl, S. L., Hendricks, J. R., Jarrard, R. D., Marques, A. C., Collins, A. G.

974 and Lieberman, B. S. 2007. Exceptionally preserved jellyfishes from the Middle

975 Cambrian. PLoS ONE 2(10), e1121. doi: 10.1371/journal.pone.0001121

976 Collins, D. 1996. The "evolution" of Anomalocaris and its classification in the arthropod Class

977 Dinocarida (nov.) and order Radiodonta (nov.). Journal of Paleontology 70, 280-293.

978 Cong, P., Ma, X., Hou, X., Edgecombe, G. D. and Strausfeld, N. J. 2014. Brain structure resolves

979 the segmental affinity of anomalocaridid appendages. Nature 513, 538-542.

980 Cong, P., Daley, A. C., Edgecombe, G. D., Hou, X. and Chen, A. 2016. Morphology of the

981 radiodontan Lyrarapax from the early Cambrian Chengjiang biota. Journal of

$982 \quad$ Paleontology 90, 663-671.

983 Cong, P., Daley, A. C., Edgecombe, G. D. and Hou, X. 2017. The functional head of the

984 Cambrian radiodontan (stem-group Euarthropoda) Amplectobelua symbrachiata. BMC

$985 \quad$ Evolutionary Biology 17, 208.

986 Cong, P. Y., Edgecombe, G. D., Daley, A. C., Guo, J., Pates, S. and Hou, X. G. 2018. New

987 radiodonts with gnathobase-like structures from the Cambrian Chengjiang biota and

988 implications for the systematics of Radiodonta. Papers in Palaeontology 4, 605-621.

989 Conway Morris, S. 1986. The community structure of the middle Cambrian Phyllopod Bed

$990 \quad$ (Burgess Shale). Palaeontology 29, 423-467. 
991 Conway Morris, S., Selden, P. A., Gunther, G., Jamison, P. G. and Robison, R. A. 2015. New 992 records of Burgess Shale-type taxa from the middle Cambrian of Utah. Journal of $993 \quad$ Paleontology 89, 411-423.

994 Conway Morris, S., Smith, R. D., Hoyal Cuthill, J., Bonino, E. \& Lerosey-Aubril, R. 2020. A 995 possible Cambrian stem-group gnathiferan-chaetognath from the Weeks Formation 996 (Miaolingian) of Utah. Journal of Paleontology 94, 624-636.

997 Daley, A. C. 2013. Anomalocaridids. Current Biology 23, R860-1.

998 Daley, A. C. and Bergström, J. 2012. The oral cone of Anomalocaris is not a classic 'Peytoia'. $999 \quad$ Naturwissenschaften 99, 501-504.

1000 Daley, A. C. and Budd, G. E. 2010. New anomalocaridid appendages from the Burgess Shale, $1001 \quad$ Canada. Palaeontology 53, 721-38.

1002 Daley, A. C. and Edgecombe, G. D. 2014. Morphology of Anomalocaris canadensis from the 1003 Burgess Shale. Journal of Paleontology 88, 68-91.

1004 Daley, A. C., Antcliffe, J. B., Drage, H. B. and Pates, S. 2018. Early fossil record of 1005 Euarthropoda and the Cambrian Explosion. Proceedings of the National Academy of $1006 \quad$ Sciences 115, 5323-5331.

1007 Daley, A. C., Budd, G. E. and Caron, J.-B. 2013. Morphology and systematics of the 1008 anomalocaridid arthropod Hurdia from the Middle Cambrian of British Columbia and 1009 Utah. Journal of Systematic Palaeontology 11, 743-87. 
1010 Daley, A. C., Budd, G. E., Caron, J.-B., Edgecombe, G. D. and Collins, D. 2009. The Burgess

1011 Shale anomalocaridid Hurdia and its significance for early euarthropod evolution. Science

$1012 \quad 323,1597-1600$.

1013 Derby, J. R., Fritz, R., Longacre, S. A., Morgan, M. and Sternbach, C. 2012. The Great

1014 American Carbonate Bank: The Geology and Economic Resources of the Cambro-

1015 Ordovician Sauk Sequence of Laurentia. American Association of Petroleum Geologists,

$1016 \quad$ Memoir 98, 528 pp.

1017 Edgecombe, G. D. And Legg, D. A. 2013. The arthropod fossil record. 393-415. In Minelli, A.,

1018 Boxshall, G. and Fusco, G. (eds). Arthropod biology and evolution. Springer.

1019 Erwin, D. H. and Tweedt, S. 2012. Ecological drivers of the Ediacaran-Cambrian diversification

1020 of Metazoa. Evolutionary Ecology 26, 417-33.

1021

Esteve, J. \& Zamora, S. 2014. Enrolled agnostids from Cambrian of Spain provide new insights

1022 about the mode of life in these forms. Bulletin of Geosciences 89, 283-90.

1023 Fletcher, T. P. and Collins, D. H. 1998. The Middle Cambrian Burgess Shale and its relationship 1024 to the Stephen Formation in the southern Canadian Rocky Mountains. Canadian Journal of Earth Sciences 35, 413-436.

1026

Foster, J. R. and Gaines, R. R. 2016. Taphonomy and Paleoecology of the "Middle" Cambrian (Series 3) Formations in Utah's West Desert: recent finds and new data. 291-336. In 
1030 Fu, D., Tong, G., Dai, T., Liu, W., Yang, Y., Zhang, Y., Cui, L., Li, L., Yun, H., Wu, Y., Sun,

1031 A., Cong, L., Pei, W., Gaines, R. R. and Zhang, X. 2019. The Qingjiang biota - a Burgess

1032 Shale-Type fossil Lagerstätte from the early Cambrian of South China. Science 363,

$1033 \quad 1338-1342$.

1034 Gaines, R. R. 2011. New Burgess Shale-type locality in the "thin" Stephen Formation, Kootenay

1035 National Park, British Columbia: stratigraphic and paleoenvironmental setting.

$1036 \quad$ Paleontographica Canadiana 31, 72-88.

1037 Gaines, R. R. 2014. Burgess Shale-type preservation and its distribution in space and time. The

1038 Paleontological Society Papers 20, 123-146.

1039 Gaines, R. R. and Droser, M. L. 2005. New approaches to understanding the mechanics of

1040 Burgess Shale-type deposits: from the micron scale to the global picture. The Sedimentary

$1041 \quad$ Record 3, 4-8.

1042 Gaines, R. R. and Droser, M. L. 2010. The paleoredox setting of Burgess Shale-type deposits.

1043 Palaeogeography, Palaeoclimatology, Palaeoecology 297, 649-661.

1044 Gaines, R. R., Kennedy, M. J. and Droser, M. L. 2005. A new hypothesis for organic

1045 preservation of Burgess Shale taxa in the Middle Cambrian Wheeler Shale, House Range,

1046 Utah. Palaeogeography, Palaeoclimatology, Palaeoecology 220, 193-205. Gámez

1047 Vintaned, J. A. G. and Zhuralev, A. Y. 2018. Comment on "Aysheaia prolata from the

1048 Utah Wheeler Formation (Drumian, Cambrian) is a frontal appendage of the radiodontan 
1049 Stanleycaris" by Stephen Pates, Allison C. Daley, and Javier Ortega-Hernández. Acta

$1050 \quad$ Palaeontologica Polonica 63, 103-104.

1051 Guo, J., Pates, S., Cong, P., Daley, A. C., Edgecombe, G. D., Chen, T. and Hou, X. 2019. A new

1052 radiodont (stem Euarthropoda) frontal appendage with a mosaic of characters from the

1053 Cambrian (Series 2 Stage 3) Chengjiang biota. Papers in Palaeontology 5, 99-110.

1054 Hagadorn J. W., Schottenfeld M. T. and McGowan D. 2010. Putting Anomalocaris on a soft-

1055 food diet? Geological Society of America Abstracts 42, 320.

1056

Halgedahl, S. L., Jarrard, R. D., Brett, C. E. and Allison, P. A. 2009. Geophysical and geological signatures of relative sea level change in the upper Wheeler Formation, Drum Mountains, West-Central Utah: a perspective into exceptional preservation of fossils.

1059 Palaeogeography, Palaeoclimatology, Palaeoecology 277, 34-56.

1060 Hally, L. A. and Paterson, J. R. 2014. Biodiversity, biofacies and biogeography of middle

1061 Cambrian (Series 3) arthropods (Trilobita and Agnostida) on the East Gondwana margin.

1062 Gondwana Research 26, 654-674.

1063 Haug, J. T., Maas, A. and Waloszek, D. 2010. Henningsmoenicaris scutula, Sandtorpia

1064 vestrogothienis gen. et sp. nov. and heterochronic events in early crustacean evolution.

1065 Transactions of the Royal Society of Edinburgh: Earth Sciences 100, 311-350.

1066 Hintze, L. F. 1980. Geologic map of Utah, scale 1:500,000. Utah Geological and Mineral

1067 Survey, Salt Lake City. 
1068 Hintze, L. F. and Robison, R. A. 1975. Middle Cambrian stratigraphy of the House, Wah Wah, 1069 and adjacent ranges in western Utah. Bulletin of the Geological Society of America 86, $1070 \quad 881-891$.

1071 Holmes, J. D., García-Bellido, D. C. and Lee, M. S. 2018. Comparisons between Cambrian 1072 Lagerstätten assemblages using multivariate, parsimony and Bayesian methods.

$1073 \quad$ Gondwana Research 55, 30-41.

1074 Hou, X. and Bergström, J. 1997. Arthropods of the Lower Cambrian Chengjiang fauna,

1075 southwewst China. Fossils \& Strata 45, 1-116.

1076 Hou, X., Bergström, J. and Ahlberg, P. 1995. Anomalocaris and other large animals in the Lower 1077 Cambrian Chengjiang Fauna of southwest China. GFF 117, 163-183.

1078 Kühl, G., Briggs, D. E. and Rust, J. 2009. A great-appendage arthropod with a radial mouth from 1079 the Lower Devonian Hunsrück Slate, Germany. Science 323, 771-773.

1080 Lerosey-Aubril, R. and Pates, S. 2018. New suspension-feeding radiodont suggests evolution of 1081 microplanktivory in Cambrian macronekton. Nature Communications 9, 3774.

1082 doi:10.1038/s41467-018-06229-7

1083 Lerosey-Aubril, R. and Skabelund, J. 2018. Messorocaris, a new sanctacaridid-like arthropod 1084 from the middle Cambrian Wheeler Formation (Utah, USA). Geological Magazine 155, $1085 \quad 181-186$. 
1086 Lerosey-Aubril, R., Skabelund, J. and Ortega-Hernández, J. 2020b. Revision of the mollisoniid

1087 chelicerate(?) Thelxiope, with a new species from the middle Cambrian Wheeler

1088 Formation of Utah. PeerJ 8, e8879. doi: http://doi.org/10.7717/peerj.8879

1089 Lerosey-Aubril, R., Hegna, T. A., Babcock, L. E., Bonino, E. and Kier, C. 2014. Arthropod

1090 appendages from the Weeks Formation Konservat-Lagerstätte: new occurrences of

1091 anomalocaridids in the Cambrian of Utah, USA. Bulletin of Geosciences 89, 269-282.

1092 Lerosey-Aubril, R., Kimmig, J., Pates, S., Skabelund, J., Weug, A. and Ortega-Hernández, J.

1093 2020a. New exceptionally-preserved panarthropods from the Drumian Wheeler

1094 Konservat-Lagerstätte of the House Range of Utah. Papers in Palaeontology. Online

1095 Early View. doi: https://doi.org/10.1002/spp2.1307

1096 Lerosey-Aubril, R., Gaines, R. R., Hegna, T. A., Ortega-Hernández, J., Van Roy, P., Kier, C. and

1097 Bonino, E. 2018. The Weeks Formation Konservat-Lagerstätte and the evolutionary

1098 transition of Cambrian marine life. Journal of the Geological Society 175, 705-715.

1099 Lieberman, B. S. 2003. A new soft-bodied fauna: the Pioche Formation of Nevada. Journal of

$1100 \quad$ Paleontology 77, 674-90.

1101 Liu, J., Lerosey-Aubril, R., Steiner, M., Dunlop, J. A., Shu, D. and Paterson, J.R. 2018. Origin of

1102 raptorial feeding in juvenile euarthropods revealed by a Cambrian radiodontan. National

$1103 \quad$ Science Review 5, 863-869.

1104 Liu, Y., Lerosey-Aubril, R., Audo, D., Zhai, D., Mai, H. and Ortega-Hernández J. 2020.

1105 Occurrence of the eudemersal radiodont Cambroraster in the early Cambrian Chengjiang 
1106 Lagerstätte and the diversity of hurdiid ecomorphotypes. Geological Magazine 157, 1200-

1107 1206. doi: https://doi.org/10.1017/S0016756820000187

1108 Maletz, J. and Steiner, M. 2015. Graptolite (Hemichordata, Pterobranchia) preservation and

1109 identification in the Cambrian Series 3. Palaeontology 58, 1073-1107.

1110 Mángano, M. G. and Buatois, L. A. 2014. Decoupling of body-plan diversification and

1111 ecological structuring during the Ediacaran-Cambrian transition: evolutionary and

1112 geobiological feedbacks. Proceedings of the Royal Society B: Biological Sciences 281,

20140038.

1114 Mángano M.G. and Buatois L.A. 2020. The rise and early evolution of animals: where do we

1115 stand from a trace-fossil perspective? Interface Focus 10, 20190103.

$1116 \quad$ doi.org/10.1098/rsfs.2019.0103

1117 Miller, J. F., Evans, K. R. and Dattilo, B. F. 2012. The Great American Carbonate Bank in the

1118 miogeocline of western central Utah: tectonic influences on sedimentation. 769-854. In

1119 Derby, J. R., Fritz, R., Longacre, S. A., Morgan, M. \& Sternbach, C. (eds). The Great

1120 American Carbonate Bank: The Geology and Economic Resources of the Cambro-

1121 Ordovician Sauk Sequence of Laurentia. American Association of Petroleum Geologists,

1122 Memoir, 98, 528 pp.

1123 Moysiuk, J. and Caron, J.-B. 2019. A new hurdiid radiodont from the Burgess Shale evinces the

1124 exploitation of Cambrian infaunal food sources. Proceedings of the Royal Society B,

1125 Biological Sciences 286, 20191079. doi: https://dx.doi.org/10.1098/rspb.2019.1079 
1126 Muscente, A. D., Schiffbauer, J. D., Broce, J., Laflamme, M., O'Donnell, K., Boag, T. H.,

1127 Meyer, M., Hawkins, A. D., Huntley, J. W., McNamara, M., MacKenzie, L. A., Stanley Jr.,

1128 G. D., Hinman, N. W., Hofmann, M. H. and MacKenzie, L. A. 2017. Exceptionally preserved

1129 fossil assemblages through geologic time and space. Gondwana Research 48, 164-188.

1130 Muscente, A. D., Prabhu, A., Zhong, H., Eleish, A., Meyer, M. B., Fox, P., Hazen, R. M. and

1131 Knoll, A. H. 2018. Quantifying ecological impacts of mass extinctions with network analysis

1132 of fossil communities. Proceedings of the National Academy of Sciences 115, 5217-5222.

1133 Nanglu, K., Caron, J.-B. and Gaines, R. R. 2020. The Burgess Shale paleocommunity with new

1134 insights from Marble Canyon, British Columbia. Paleobiology 46, 58-81.

1135 Nielsen, C. 1995. Animal evolution: Interrelationships of the living phyla. Oxford University

1136 Press, Oxford, 402 pp.

1137 O'Brien, L. J. and Caron, J.-B. 2016. Paleocommunity analysis of the Burgess Shale Tulip Beds,

1138 Mount Stephen, British Columbia: comparison with the Walcott Quarry and implications for

1139 community variation in the Burgess Shale. Paleobiology 42, 27-53.

1140 Ortega-Hernández, J. 2016. Making sense of 'lower' and ‘upper' stem-group Euarthropoda, with

1141 comments on the strict use of the name Arthropoda von Siebold, 1848. Biological Reviews 91, $1142 \quad 255-273$.

1143 Pates, S. and Daley, A. C. 2017. Caryosyntrips: a radiodontan from the Cambrian of Spain, USA 1144 and Canada. Papers in Palaeontology 3, 461-470. 
1145 Pates, S. and Daley, A. C. 2019. The Kinzers Formation (Pennsylvania, USA): the most diverse

1146 assemblage of Cambrian Stage 4 radiodonts. Geological Magazine 156, 1233-1246.

1147 Pates, S., Daley, A. C. and Butterfield, N. J. 2019a. First report of paired ventral endites in a

1148 hurdiid radiodont. Zoological Letters 5, 18. doi: https://doi.org/10.1186/s40851-019-0132-4

1149 Pates, S., Daley, A. C. and Lieberman, B. S. 2018a. Hurdiid radiodontans from the middle

1150 Cambrian (Series 3) of Utah. Journal of Paleontology 92, 99-113.

1151 Pates, S., Daley, A. C. and Ortega-Hernández, J. 2017. Aysheaia prolata from the Utah Wheeler

1152 Formation (Drumian, Cambrian) is a frontal appendage of the radiodontan Stanleycaris. Acta

1153 Palaeontologica Polonica 62, 619-625.

1154 Pates, S., Daley, A. C. and Ortega-Hernández, J. 2018b. Reply to Comment on “Aysheaia

1155 prolata from the Utah Wheeler Formation (Drumian, Cambrian) is a frontal appendage of the

1156 radiodontan Stanleycaris" with the formal description of Stanleycaris. Acta Palaeontologica

1157 Polonica 63, 105-110.

1158 Pates, S., Botting, J. P., McCobb, L. M. E. and Muir, L. A. 2020. A miniature Ordovician hurdiid

1159 from Wales demonstrates the adaptability of Radiodonta. Royal Society Open Science 7,

1160 200459. doi: http://dx.doi.org/10.1098/rsos.200459

1161 Pates, S., Daley, A. C., Edgecombe, G. D., Cong, P., and Lieberman, B. S. 2019b. Systematics,

1162 preservation and biogeography of radiodonts from the southern Great Basin, USA, during the

1163 upper Dyeran (Cambrian Series 2, Stage 4). Papers in Palaeontology. Online early view.

1164 doi.org/10.1002/spp2.1277 
1165 Pates, S., Lerosey-Aubril, R., Daley, A. C., Kier, C., Bonino, E. and Ortega-Hernández, J. 2020 b.

1166 Supplementary data for 'The diverse radiodont fauna from the Marjum Formation of Utah,

1167 USA (Cambrian, Drumian)'. Open Science Framework. Retrieved from osf.io/y6xwc.

1168 doi.org/10.17605/OSF.IO/Y6XWC

1169 Peng, S. C., Babcock, L. E. and Cooper, R. A. 2012. The Cambrian Period. In Gradstein, F. M.,

1170 Ogg, J. G., Schmitz, M. and Ogg, G. J. (eds), The Geologic Time Scale 2012, 451-502.

$1171 \quad$ Elsevier, Boston.

1172 Peng, S. C. and Robison, R. A. 2000. Agnostoid biostratigraphy across the Middle-Upper

1173 Cambrian Boundary in China. Paleontological Society Memoir 53, 104. (Supplement to

1174 Journal of Paleontology 74).

1175 Pegel, T. V. 2000. Evolution of trilobite biofacies in Cambrian basins of the Siberian Platform.

1176 Journal of Paleontology 74, 1000-19.

1177 Rees, M. N. 1986. A fault-controlled trough through a carbonate platform: the Middle Cambrian

1178 House Range Embayment. Geological Society of America Bulletin 97, 1054-1069.

1179 Rigby, J. K., Church, S. B. and Anderson, N. K. 2010. Middle Cambrian Sponges from the Drum

1180 Mountains and House Range in Western Utah. Journal of Paleontology 84, 66-78.

1181 Robison, R. A. 1964. Upper Middle Cambrian stratigraphy of western Utah. Geological Society

$1182 \quad$ of America Bulletin 75, 995-1010.

1183 Robison, R. A. 1976. Middle Cambrian trilobite biostratigraphy of the Great Basin. Brigham

1184 Young University Geology Studies 23, 93-109. 
1185 Robison, R. A. 1991. Middle Cambrian biotic diversity: examples from four Utah Lagerstätten.

1186 77-98. In Simonetta, A. and Conway Morris, S. (eds). The Early Evolution of Metazoa

1187 and the Significance of Problematic Taxa. Cambridge University Press, Cambridge, U.K.

1188 Robison, R. A. and Babcock, L. E. 2011. Systematics, paleobiology, and taphonomy of some

1189 exceptionally preserved trilobites from Cambrian Lagerstätten of Utah. Kansas University

$1190 \quad$ Paleontological Contributions 5, 1-47.

1191 Robison, R. A. and Richards, B. C. 1981. Larger bivalve arthropods from the Middle Cambrian

1192 of Utah. The University of Kansas Paleontological Contributions 106, 1-28.

1193 Robison, R. A., Babcock, L. E. and Gunther, V. G. 2015. Exceptional Cambrian fossils from

1194 Utah: a window into the age of trilobites. Utah Geological Survey, Salt Lake City,

1195 Miscellaneous Publication 15-1, 1-97.

1196 Rolfe, W. D. I. 1962. Two new arthropod carapaces from the Burgess Shale (Middle Cambrian)

1197 of Canada. Breviora 160, 1-9.

1198 Rueden, C. T., Schindelin, J., Hiner, M.C., DeZonia, B. E., Walter, A. E., Arena, E. T. and

1199 Eliceiri, K. W., 2017. ImageJ2: ImageJ for the next generation of scientific image data.

1200 BMC Bioinformatics 18, 529.

1201 Saleh, F., Antcliffe, J.B., Lefebvre, B., Pittet, B., Laibl, L., Peris, F.P., Lustri, L., Gueriau, P. and 
1204 Schneider, C. A., Rasband, W. S. and Eliceiri, K. W. 2012. NIH Image to ImageJ: 25 years of 1205 image analysis. Nature Methods 9, 671-675.

1206 Sheppard, K. A., Rival, D. E. and Caron, J.-B. 2018. On the hydrodynamics of Anomalocaris tail 1207 fins. Integrative and Comparative Biology 58, 703-711.

1208 Smith, D. D. 2007. Sequence stratigraphy of the middle Cambrian Marjum Formation: response

1209 of sedimentary facies and biota to sea-level changes. Unpublished MSc. Thesis, Utah State

$1210 \quad$ University, Logan. 156 pp.

1211 Smith, M. R. 2015. A palaeoscolecid worm from the Burgess Shale. Palaeontology 58, 973-979.

1212 Sundberg, F. A. 1991. Paleogeography of western Utah and eastern Nevada during the

1213 Ehmaniella biochron (Middle Cambrian). In Cooper, J. D. and Stevens, C. H. (eds.),

1214 Paleozoic Paleogeography of the Western United States II. Pacific Section SEPM 67, 387-99.

1215 Sun, Z., Zeng, H. and Zhao, F. 2020. A new middle Cambrian radiodont from North China:

1216 Implications for morphological disparity and spatial distribution of hurdiids.

1217 Palaeogeography, Palaeoclimatology, Palaeoecology, 558, 109947.

1218 Torsvik, T. H. and Cocks, L. R. 2017. Earth History and Palaeogeography. Cambridge

$1219 \quad$ University Press, Cambridge, 317 pp.

1220 Usami, Y. 2006. Theoretical study on the body form and swimming pattern of Anomalocaris

1221 based on hydrodynamic simulation. Journal of Theoretical Biology 238, 11-17. 
1222 Vannier, J., Chen, J. Y., Huang, D. Y., Charbonnier, S. and Wang, X. Q. 2006. The early

1223 Cambrian origin of thylacocephalan arthropods. Acta Palaeontologica Polonica 51, 201-

214.

1225 Vannier, J., Liu, J., Lerosey-Aubril, R., Vinther, J. and Daley, A. C. 2014. Sophisticated

1226 digestive systems in early arthropods. Nature Communications 5, 3641.

1227 doi: $10.1038 /$ ncomms4641

1228 Van Roy, P., Daley, A. C. and Briggs, D. E. 2015. Anomalocaridid trunk limb homology

1229 revealed by a giant filter-feeder with paired flaps. Nature 522, 77-80.

1230 Vinther, J., Stein, M., Longrich, N. R. and Harper, D. A. 2014. A suspension-feeding

1231 anomalocarid from the Early Cambrian. Nature 507, 496-9.

1232 Whalen, C. D. and Briggs, D. E. (2018). The Palaeozoic colonization of the water column and

1233 the rise of global nekton. Proceedings of the Royal Society B: Biological Sciences

$1234 \quad \mathbf{2 8 5 ( 1 8 8 3 )}, 20180883$.

1235 Walcott, C. D. 1911. Cambrian geology and paleontology II. Middle Cambrian holothurians and

1236 medusa. Smithsonian Miscellaneous Collections 57, 41-68.

1237 Walcott, C. D. 1912. Cambrian geology and paleontology II. Middle Cambrian Branchiopoda,

1238 Malacostraca, Trilobita and Merostomata. Smithsonian Miscellaneous Collections 57,

$1239 \quad 145-228$. 
1240 Whittington, H. B. and Briggs, D. E. G.1985. The largest Cambrian animal, Anomalocaris,

1241 Burgess Shale, British-Columbia. Philosophical Transactions of the Royal Society of

$1242 \quad$ London, Series B 309, 569-609.

1243 Young, F. J. and Vinther, J. 2017. Onychophoran-like myoanatomy of the Cambrian gilled

1244 lobopodian Pambdelurion whittingtoni. Palaeontology 60, 27-54.

1245 Zeng, H., Zhao, F., Yin, Z. and Zhu, M. 2018. Morphology of diverse radiodontan head sclerites

1246 from the early Cambrian Chengjiang Lagerstätte, south-west China. Journal of Systematic

1247 Palaeontology 16, 1-37.

1248 
1249 Figure 1. Radiodont occurrences in the Marjum Formation (Cambrian: Drumian) in the

1250 House Range of Utah, USA. (A) Map of western USA showing the locations of the main

1251 Cambrian Konservat-Lagerstätten (circles) of the Great Basin (light grey area), including the

1252 Marjum Formation in the House Range (HR) of western Utah (credit: Rudy Lerosey-Aubril). (B)

1253 Simplified geological map of the central House Range (credit: Rudy Lerosey-Aubril), showing

1254 the geographic distribution of the Marjum Formation and the localities that have yielded

1255 radiodont fossils: Kells Knolls (Buccaspinea cooperi gen. et sp. nov.), Red Wash (Caryosyntrips

1256 sp.), and Sponge Gully (Peytoia nathorsti). A fourth radiodont, Pahvantia hastata, occurs in the

1257 Marjum Formation, but the known material of this taxon is of uncertain origin within the House

1258 Range. Data relating to the spatial distributions of Cambrian strata are derived from Hintze

1259 (1980).

1260

1261 Figure 2. Buccaspinea cooperi gen. et sp. nov. from the Marjum Formation (Cambrian:

1262 Drumian) in the House Range of Utah, USA. (A) Part of holotype specimen (BPM 1108a),

1263 general view. (B) Interpretative drawing of (A) (credit: Stephen Pates). Abbreviations: $f l$,

1264 triangular lateral flaps; lfa, left frontal appendage; lin, linear feature on posteriormost preserved

1265 body segment; oc, oral cone; om, organic matter inside central opening of the oral cone; $r f a$, right

1266 frontal appendage; $s b$, setal blade.

1267 
1268 Figure 3. Buccaspinea cooperi gen. et sp. nov. from the Marjum Formation (Cambrian:

1269 Drumian) in the House Range of Utah, USA. (A) Counterpart of holotype specimen (BPM

1270 1108b), general view (mirrored). (B) Interpretative drawing of (A) (credit: Stephen Pates).

1271 Abbreviations: $f l$, triangular lateral flaps; lfa, left frontal appendage; lin, linear feature on

1272 posteriormost preserved body segment; oc, oral cone; om, organic matter; $r f a$, right frontal

1273 appendage; $s b$, setal blade.

1274

1275 Figure 4. Buccaspinea cooperi gen. et sp. nov. from the Marjum Formation (Cambrian:

1276 Drumian) in the House Range of Utah, USA. (A) Part of holotype specimen (BPM 1108a),

1277 detailed view of the oral cone and frontal appendages; black arrows indicate longest auxiliary

1278 spines used for measurements in the main text. (B) Interpretative drawing of (A) (credit: Stephen

1279 Pates). Abbreviations: aux, auxiliary spines; de, distal endite; $d s$, dorsal spine; en, plate-like

1280 endite; lfa, left frontal appendage; $l p$, large plate in oral cone; $o c$, oral cone; om, organic matter

1281 inside central opening of the oral cone; $p d$, podomere; $r f a$, right frontal appendage; $s$, shaft

1282 podomere; $s b$, setal blade; $s p$, small plate in oral cone; $t$, teeth on inner margin of oral cone; $t s$,

1283 terminal spine.

1284

1285 Figure 5. Buccaspinea cooperi gen. et sp. nov. from the Marjum Formation (Cambrian:

1286 Drumian) in the House Range of Utah, USA. (A) Counterpart of holotype specimen (BPM

1287 1108b), detailed view of the oral cone and frontal appendages; (B) Interpretative drawing of (A) 
1288 (credit: Stephen Pates). Abbreviations: aux, auxiliary spines; de, distal endite; $d s$, dorsal spine;

$1289 e n$, plate-like endite; $i r$, inner row of teeth within oral cone; lfa, left frontal appendage; lp, large

1290 plate; $o c$, oral cone; om, organic matter inside central opening of the oral cone; $r f a$, right frontal

1291 appendage; $s b$, setal blade; $t$, teeth on inner margin of oral cone; $t s$, terminal spine.

1292

1293 Figure 6. Buccaspinea cooperi gen. et sp. nov. from the Marjum Formation (Cambrian:

1294 Drumian) in the House Range of Utah, USA. (A, B) Part of holotype specimen (BPM 1108a),

1295 detailed views of the square opening (A) and right frontal appendage (B). (A) details tricuspid

1296 teeth with large central point (black arrow) flanked by two smaller points (white arrows). (B)

1297 shows relationships of terminal spine (pink arrow), auxiliary spines on distalmost plate-like

1298 endite (black arrows), and distal endites (white arrows). (C) Counterpart of holotype specimen

1299 (BPM 1108b), detailed view (mirrored) of posterior flaps showing transverse lines; photographed

1300 under water with cross polarized lighting.

1301

1302 Figure 7. Pahvantia hastata Robison \& Richards, 1981, from the Marjum Formation

1303 (Cambrian: Drumian) in the House Range of Utah, USA. All specimens are central carapace

1304 elements photographed using cross-polarization, with their anterior ends towards the top. (A)

1305 Specimen UMNH.IP6694. (B, D) Specimen UMNH.IP6101, general view (B) and detailed view

1306 of the posterior marginal spines (D). (C) Specimen UMNH.IP6105. (E-G) Detailed views of

1307 posterior marginal spines in specimens KUMIP134879 (E), UMNH.IP6088 (F), and 
1308 UMNH.IP6093 (G). Abbreviations: as, anterior spine; bo, boundary between main region and

1309 lateral extension; $c w$, compaction wrinkle; le, lateral extension ('lappet'); $l i$, lateral indent; $m i$,

1310 median indent; $m r$, main region; $m s$, marginal spine; $n r$, nuchal region; on, ocular notch.

1311

1312 Figure 8. Caryosyntrips camurus? from the Marjum Formation (Cambrian: Drumian) in

1313 the House Range of Utah, USA. (A, B) Specimen BPM1100. (A) general view using cross

1314 polarized light. (B) Interpretative drawing (credit: Rudy Lerosey-Aubril). Abbreviations: $d s$ ?

1315 projection from dorsal surface, potentially a spine; en, paired endites; $p m$, bell-shaped posterior

1316 margin.

1317

1318 Figure 9. Caryosyntrips camurus from the Marjum Formation (Cambrian: Drumian) in the

1319 House Range of Utah, USA. (A-C) Specimen UMNH.IP6122. (A, C) general view of (A) part

1320 and (C) counterpart immersed in water (cross polarized light). (B) Composite interpretative

1321 drawing, combining details of both part and counterpart (credit: Rudy Lerosey-Aubril).

1322 Abbreviations: ap2?, possible remains of a second appendage; $d s ?$ projection from dorsal

1323 surface, potentially a spine; en, endites; mo, mineral outgrowth; $p m$, notched posterior margin.

1327 from the House Range of Utah, USA. (A) Agnostoid Itagnostus interstrictus, UMNH.IP5621. 
1328 (B) Medusiform fossil, UU07021.03 (from Cartwright et al. 2007). (C) Radiodont Peytoia,

1329 USNM.PAL374593. (D) 'Bivalved arthropod’ Tuzoia, KUMIP153917a (credit: Julien Kimmig).

1330 (E) 'Bivalved arthropod' Perspicaris, UMNH.IP6323. (F) 'Bivalved arthropod' Branchiocaris,

1331 KUMIP204797 (credit: Julien Kimmig).

1332

1333 Supplementary Figure 1. Details of boundaries between endites on appendages of the

1334 holotype of Buccaspinea cooperi from the Marjum Formation (Cambrian: Drumian) in the

1335 House Range of Utah, USA. (A, C) BPM 1108b, counterpart of holotype. (B, D) BPM 1108a,

1336 part of holotype. Numbers indicate plate-like endites, numbered from proximal to distal. Arrows

1337 indicate boundaries between endites. 


\section{Figure 1}

Radiodont occurrences in the Cambrian (Drumian) Marjum Formation in the House Range of Utah, USA.

(A) Map of western USA showing the locations of the main Cambrian Konservat-Lagerstätten (circles) of the Great Basin (light grey area), including the Marjum Formation in the House Range (HR) of western Utah (credit: Rudy Lerosey-Aubril). (B) Simplified geological map of the central House Range (credit: Rudy Lerosey-Aubril), showing the geographic distribution of the Marjum Formation and the localities that have yielded radiodont fossils: Kells Knolls (Buccaspinea cooperi gen. et sp. nov.), Red Wash (Caryosyntrips sp.), and Sponge Gully (Peytoia nathorsti). A fourth radiodont, Pahvantia hastata, occurs in the Marjum Formation, but the known material of this taxon is of uncertain origin within the House Range. Data relating to the spatial distributions of Cambrian strata are derived from Hintze (1980). 


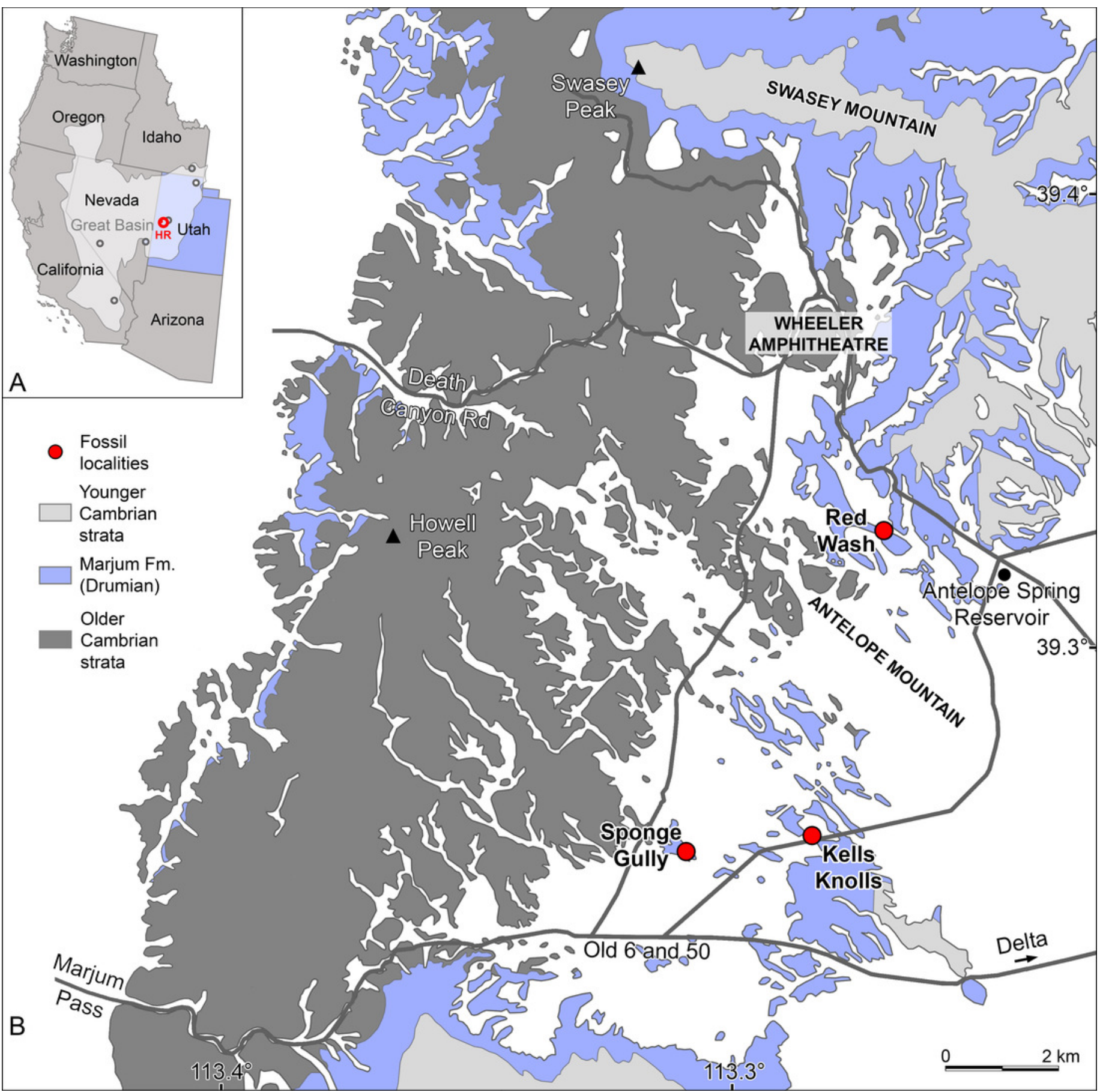




\section{Figure 2}

Buccaspinea cooperi gen. et sp. nov. from the Cambrian (Drumian) Marjum Formation in the House Range of Utah, USA.

(A) Part of holotype specimen (BPM 1108a), general view. (B) Interpretative drawing of (A) (credit: Stephen Pates). Abbreviations: $f$, triangular lateral flaps; Ifa, left frontal appendage; lin, linear feature on posteriormost preserved body segment; $O C$, oral cone; om, organic matter inside central opening of the oral cone; rfa, right frontal appendage; sb, setal blade. 

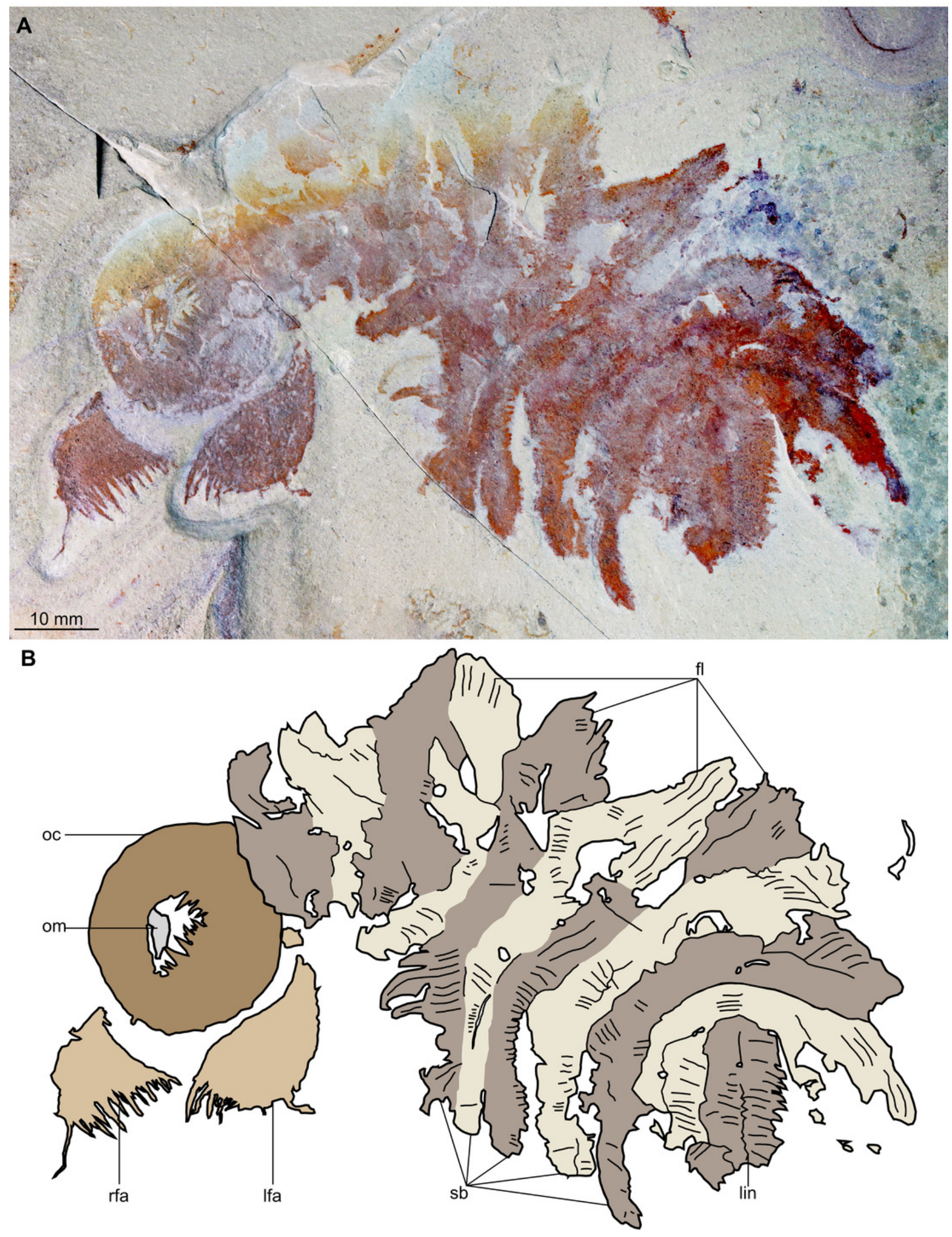

$10 \mathrm{~mm}$ 


\section{Figure 3}

Buccaspinea cooperi gen. et sp. nov. from the Cambrian (Drumian) Marjum Formation in the House Range of Utah, USA.

(A) Counterpart of holotype specimen (BPM 1108b), general view (mirrored). (B)

Interpretative drawing of (A) (credit: Stephen Pates). Abbreviations: fl, triangular lateral flaps;

Ifa, left frontal appendage; lin, linear feature on posteriormost preserved body segment; oc, oral cone; om, organic matter; rfa, right frontal appendage; $s b$, setal blade. 

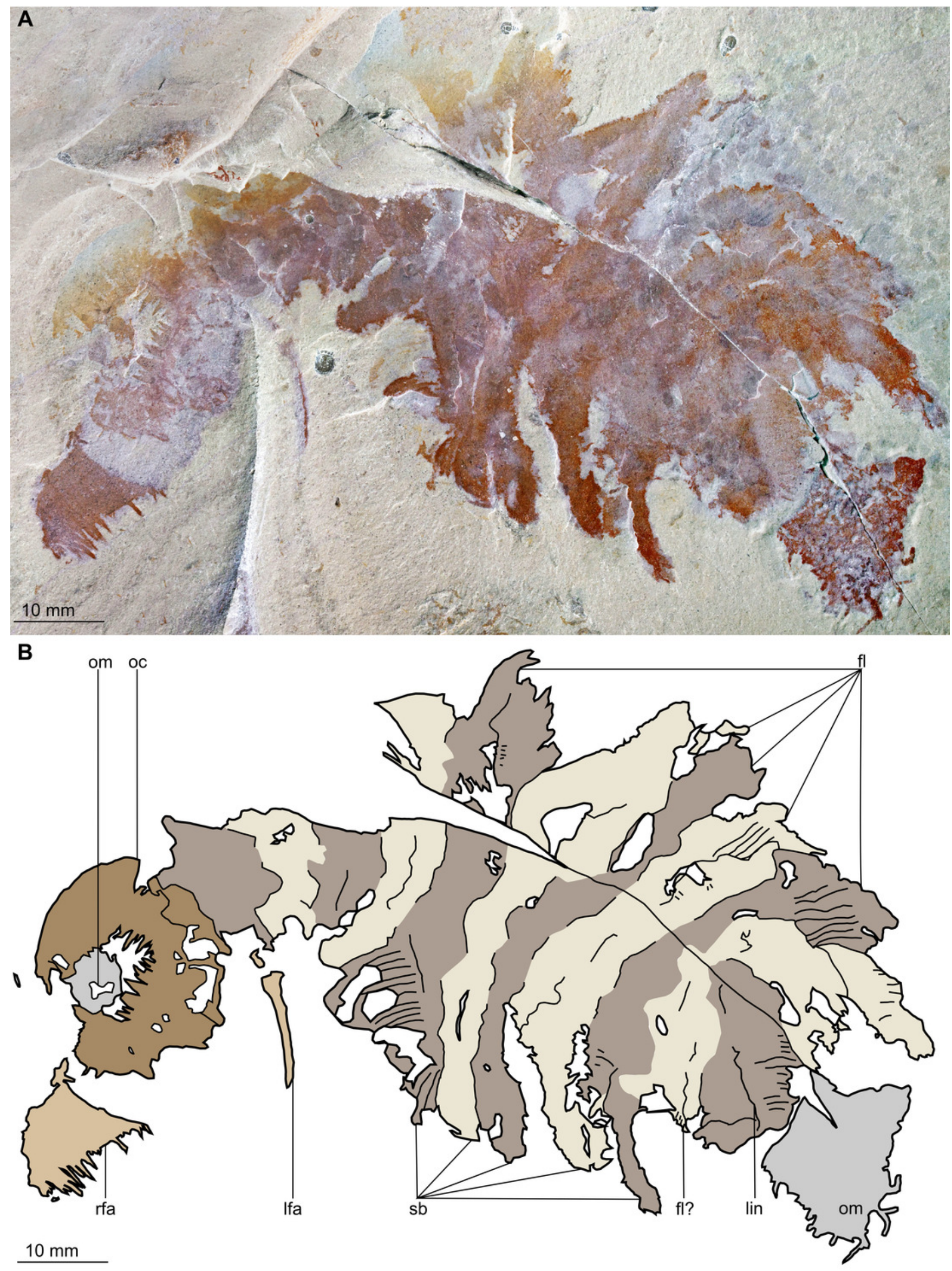


\section{Figure 4}

Figure 4. Buccaspinea cooperi gen. et sp. nov. from the Marjum Formation (Cambrian: Drumian) in the House Range of Utah, USA.

(A) Part of holotype specimen (BPM 1108a), detailed view of the oral cone and frontal appendages; black arrows indicate longest auxiliary spines used for measurements in the main text. (B) Interpretative drawing of (A) (credit: Stephen Pates). Abbreviations: aux, auxiliary spines; de, distal endite; $d s$, dorsal spine; en, plate-like endite; Ifa, left frontal appendage; Ip, large plate in oral cone; oc, oral cone; om, organic matter inside central opening of the oral cone; $p d$, podomere; rfa, right frontal appendage; $s$, shaft podomere; $s b$, setal blade; $s p$, small plate in oral cone; $t$, teeth on inner margin of oral cone; ts, terminal spine. 

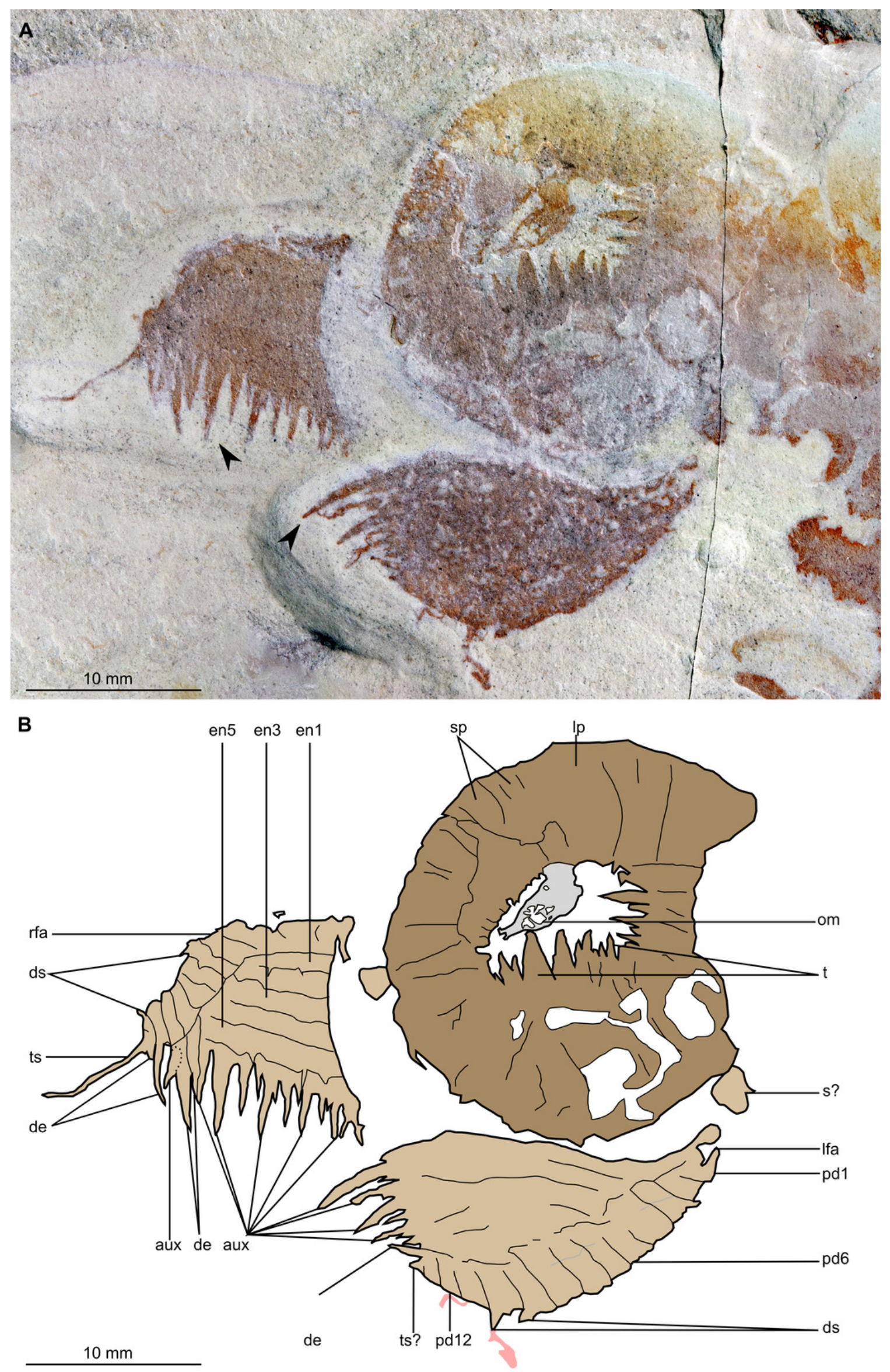


\section{Figure 5}

Buccaspinea cooperi gen. et sp. nov. from the Cambrian (Drumian) Marjum Formation in the House Range of Utah, USA.

(A) Counterpart of holotype specimen (BPM 1108b), detailed view of the oral cone and frontal appendages; (B) Interpretative drawing of (A) (credit: Stephen Pates). Abbreviations: aux, auxiliary spines; de, distal endite; $d s$, dorsal spine; en, plate-like endite; ir, inner row of teeth within oral cone; Ifa, left frontal appendage; Ip, large plate; $o c$, oral cone; om, organic matter inside central opening of the oral cone; $r f a$, right frontal appendage; $s b$, setal blade; $t$, teeth on inner margin of oral cone; ts, terminal spine. 


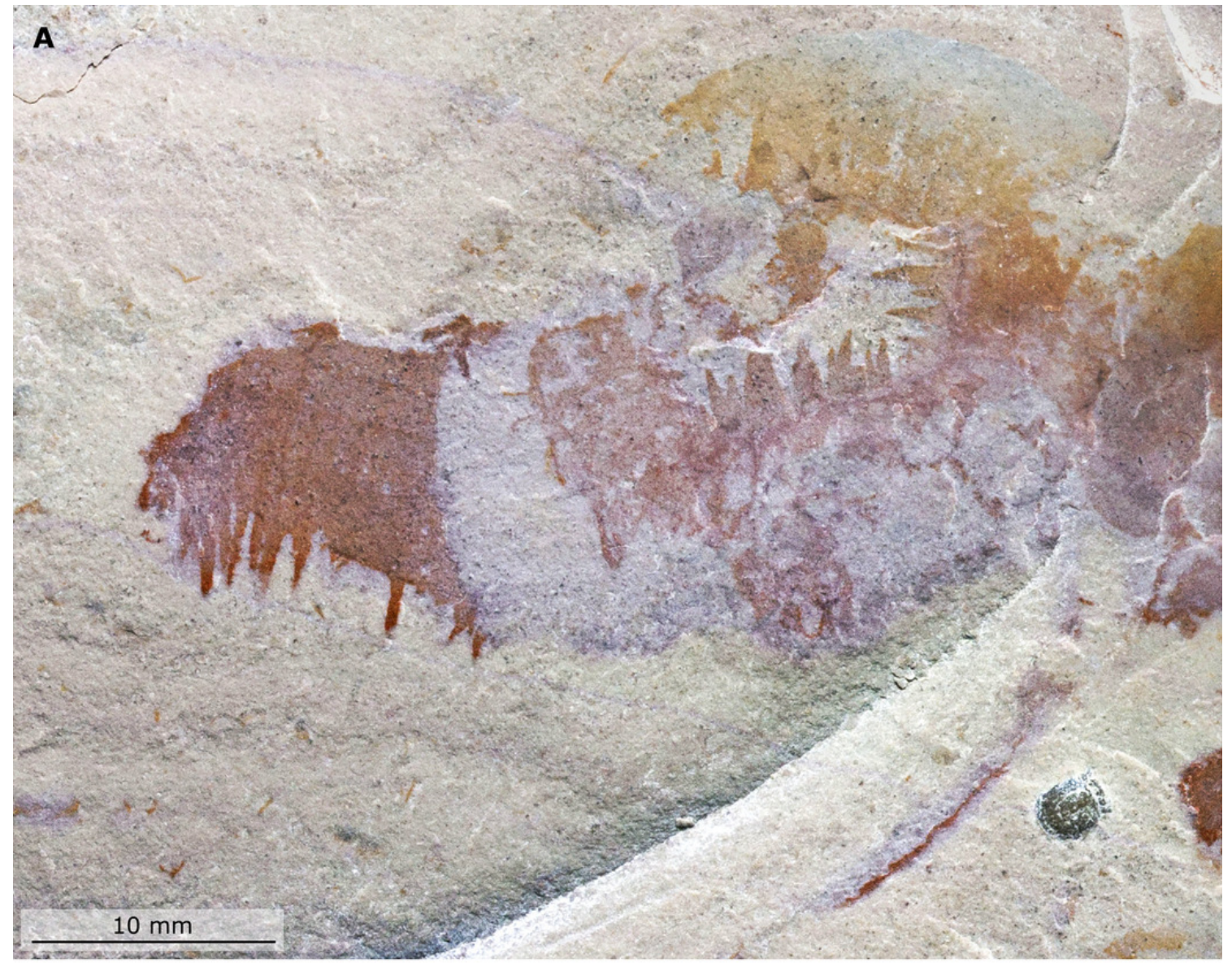

B

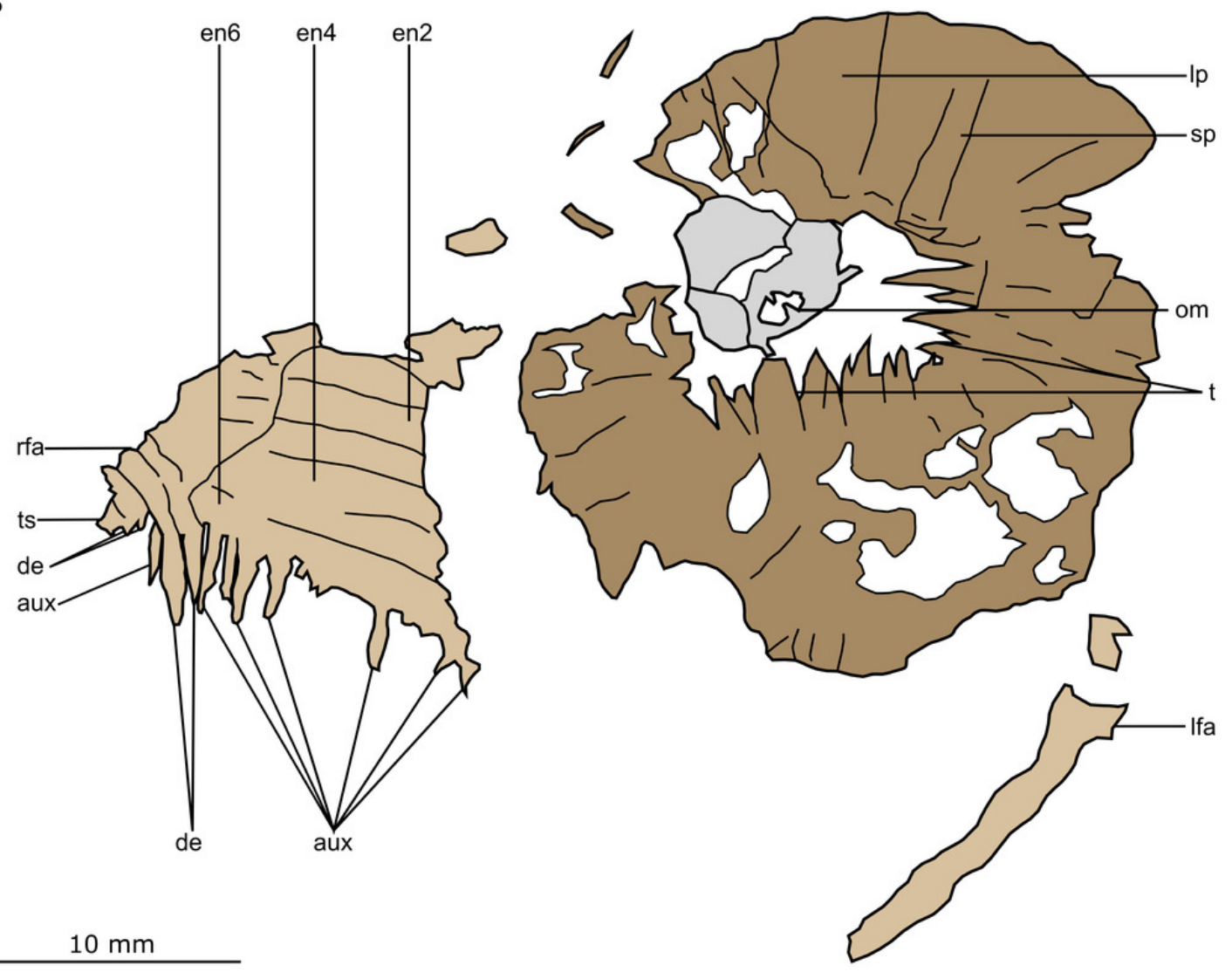

Peer) reviewing PDF | (2020:08:52266:2:0:NEW 11 Nov 2020) 


\section{Figure 6}

Figure 6. Buccaspinea cooperi gen. et sp. nov. from the Marjum Formation (Cambrian: Drumian) in the House Range of Utah, USA.

(A, B) Part of holotype specimen (BPM 1108a), detailed views of the square opening (A) and right frontal appendage (B). (A) details tricuspid teeth with large central point (black arrow) flanked by two smaller points (white arrows). (B) shows relationships of terminal spine (pink arrow), auxiliary spines on distalmost plate-like endite (black arrows), and distal endites (white arrows). (C) Counterpart of holotype specimen (BPM 1108b), detailed view (mirrored) of posterior flaps showing transverse lines; photographed under water with cross polarized lighting. 

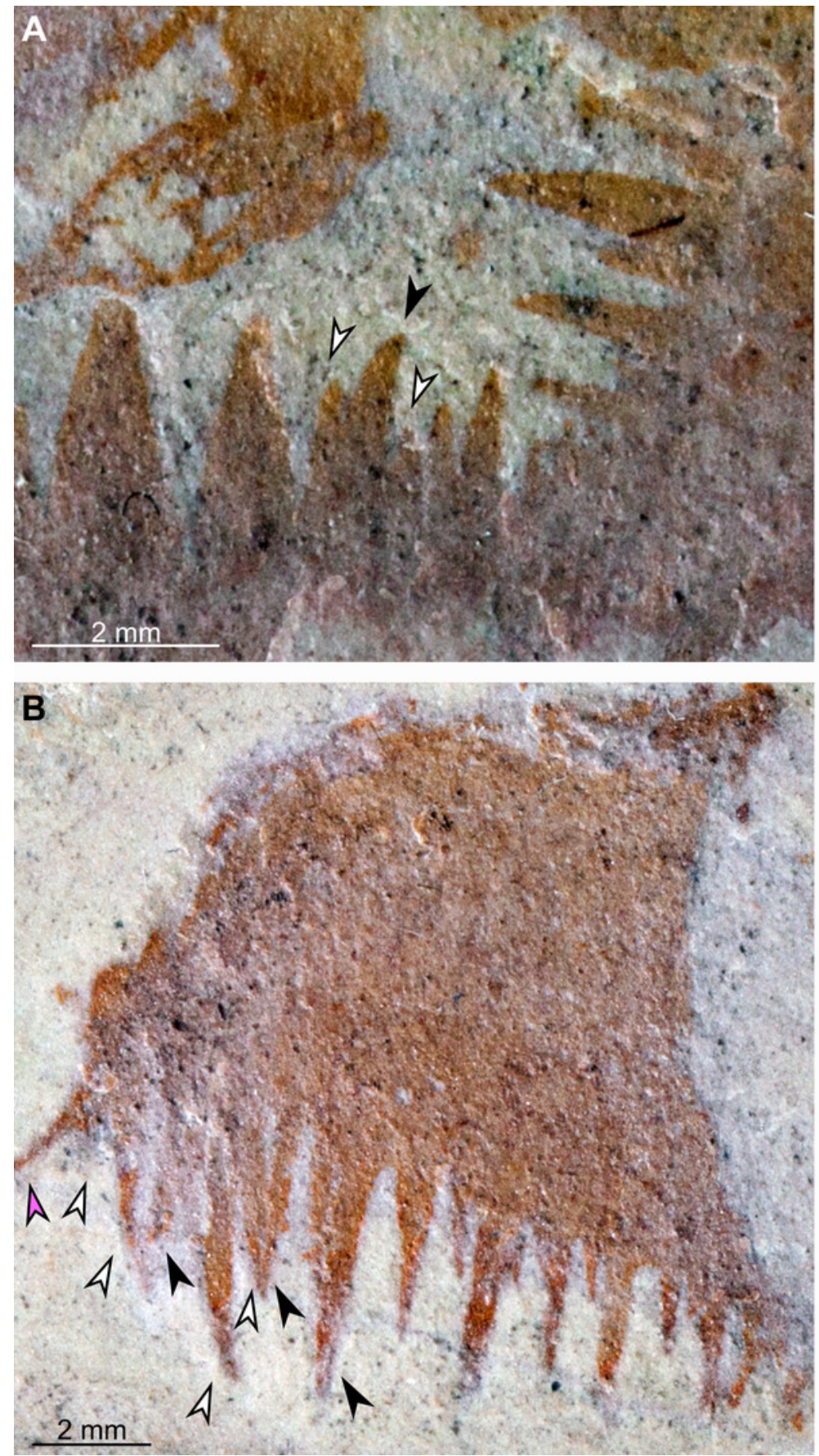
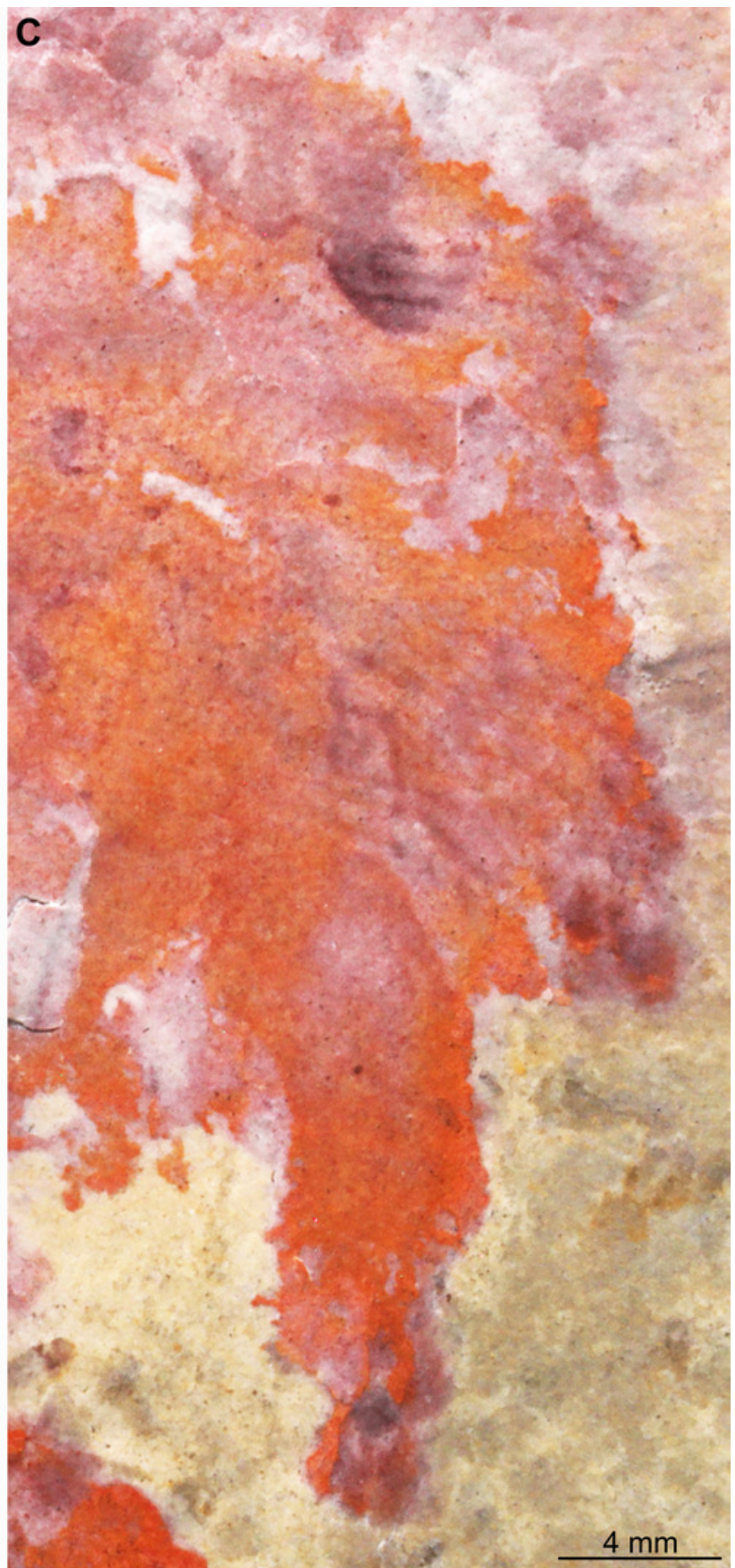


\section{Figure 7}

Pahvantia hastata Robison \& Richards, 1981, from the Cambrian (Drumian) Marjum Formation in the House Range of Utah, USA.

All specimens are central carapace elements photographed using cross-polarization, with their anterior ends towards the top. (A) Specimen UMNH.IP6694. (B, D) Specimen UMNH.IP6101, general view (B) and detailed view of the posterior marginal spines (D). (C) Specimen UMNH.IP6105. (E-G) Detailed views of posterior marginal spines in specimens KUMIP134879 (E), UMNH.IP6088 (F), and UMNH.IP6093 (G). Abbreviations: as, anterior spine; bo, boundary between main region and lateral extension; $c w$, compaction wrinkle; le, lateral extension ('lappet'); li, lateral indent; $m i$, median indent; $m r$, main region; $m s$, marginal spine; $n r$, nuchal region; on, ocular notch. 

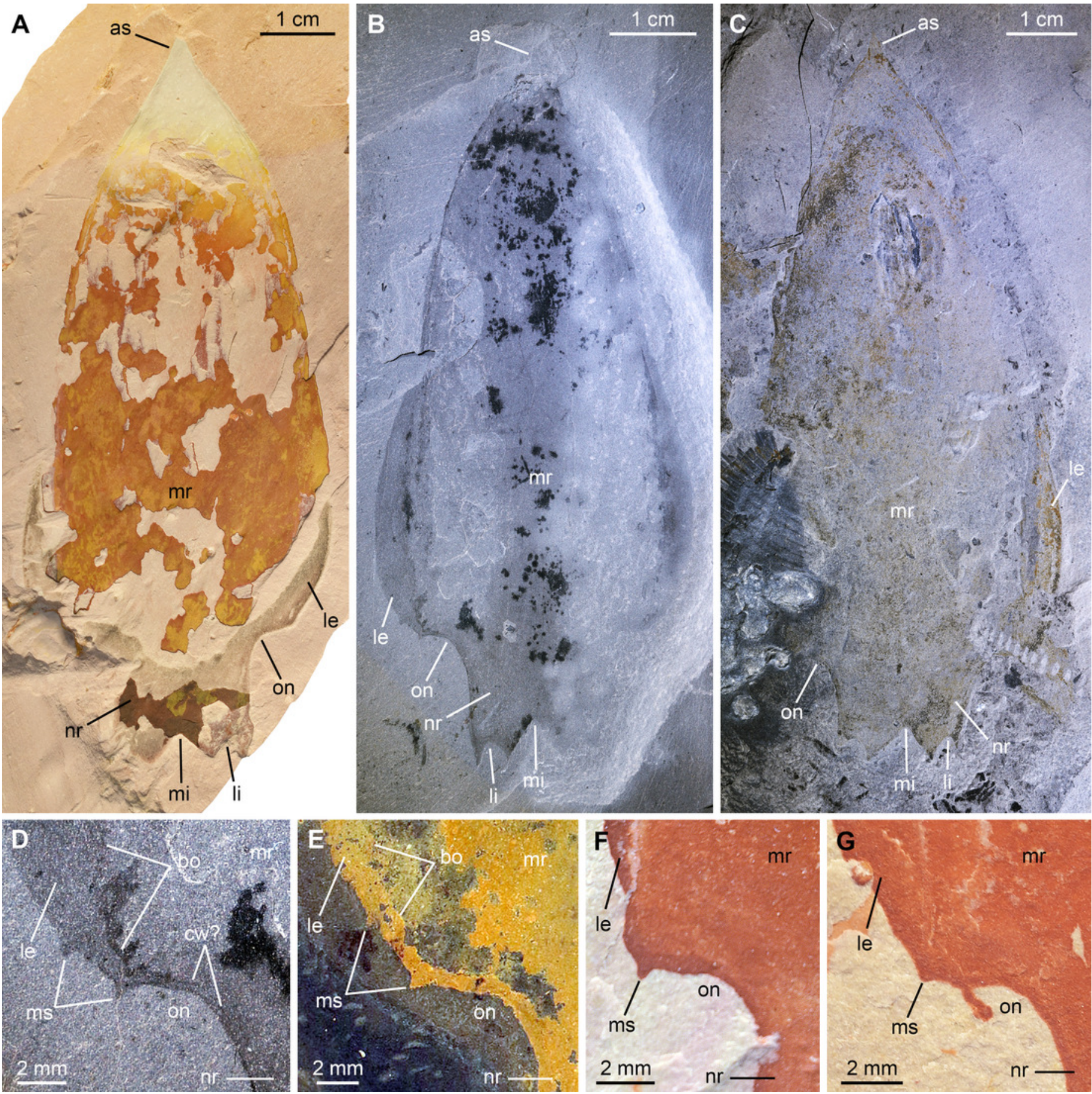


\section{Figure 8}

Caryosyntrips camurus? from the Cambrian (Drumian) Marjum Formation in the House Range of Utah, USA.

(A, B) Specimen BPM1100. (A) general view using cross polarized light. (B) Interpretative drawing (credit: Rudy Lerosey-Aubril). Abbreviations: $d s$ ? projection from dorsal surface, potentially a spine; en, paired endites; pm, bell-shaped posterior margin.

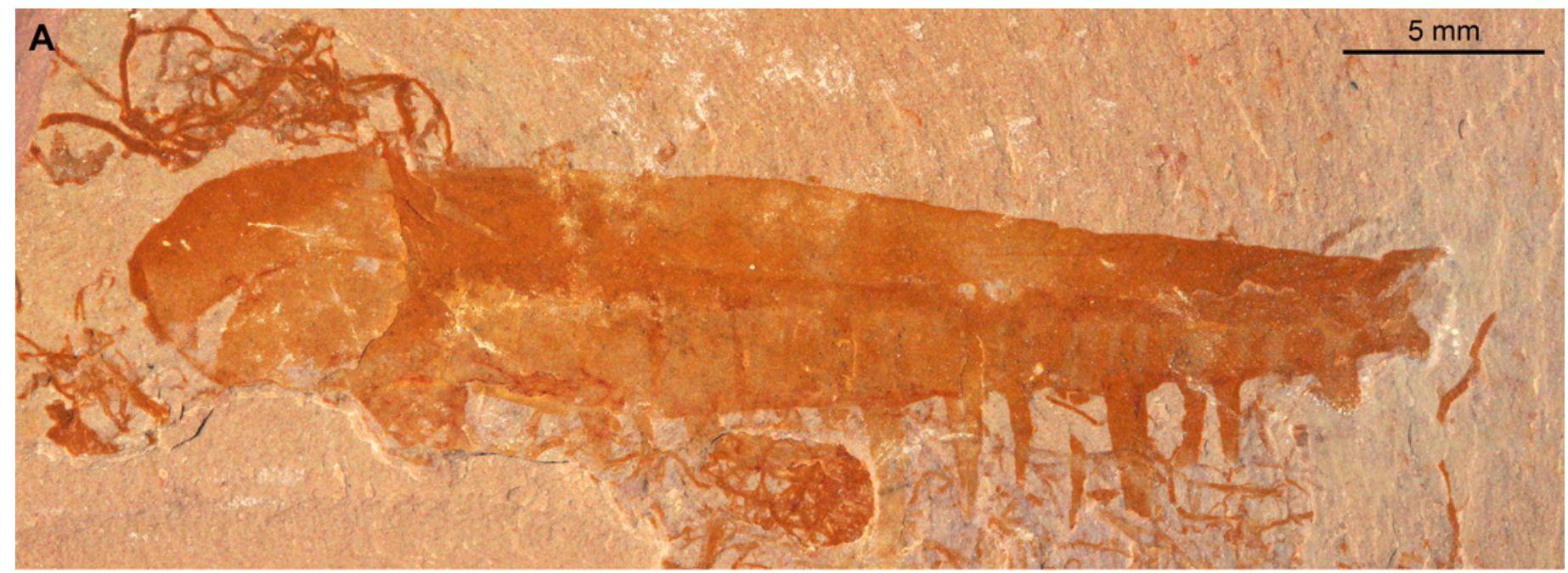

B

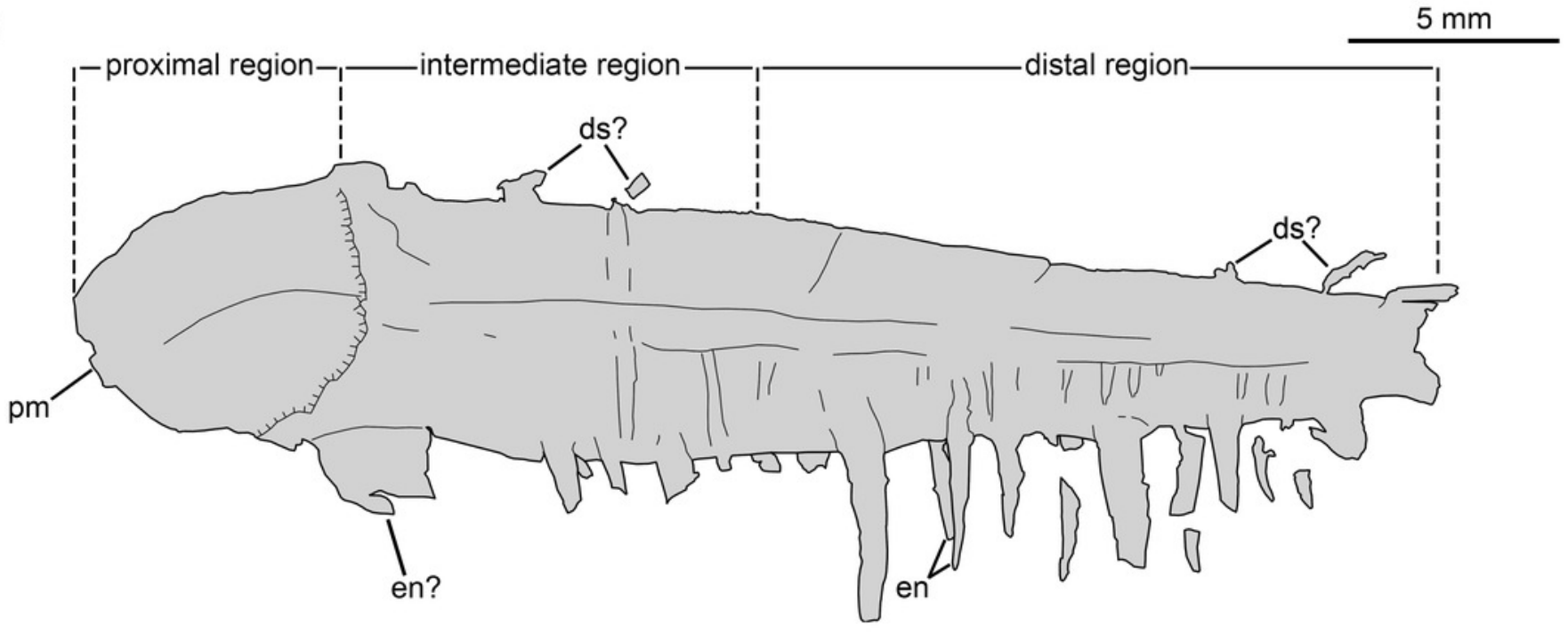




\section{Figure 9}

Caryosyntrips camurus from the Cambrian (Drumian) Marjum Formation in the House Range of Utah, USA.

(A-C) Specimen UMNH.IP6122. (A, C) general view of (A) part and (C) counterpart immersed in water (cross polarized light). (B) Composite interpretative drawing, combining details of both part and counterpart (credit: Rudy Lerosey-Aubril). Abbreviations: ap2?, possible remains of a second appendage; $d s$ ? projection from dorsal surface, potentially a spine; en, endites; mo, mineral outgrowth; $p m$, notched posterior margin. 

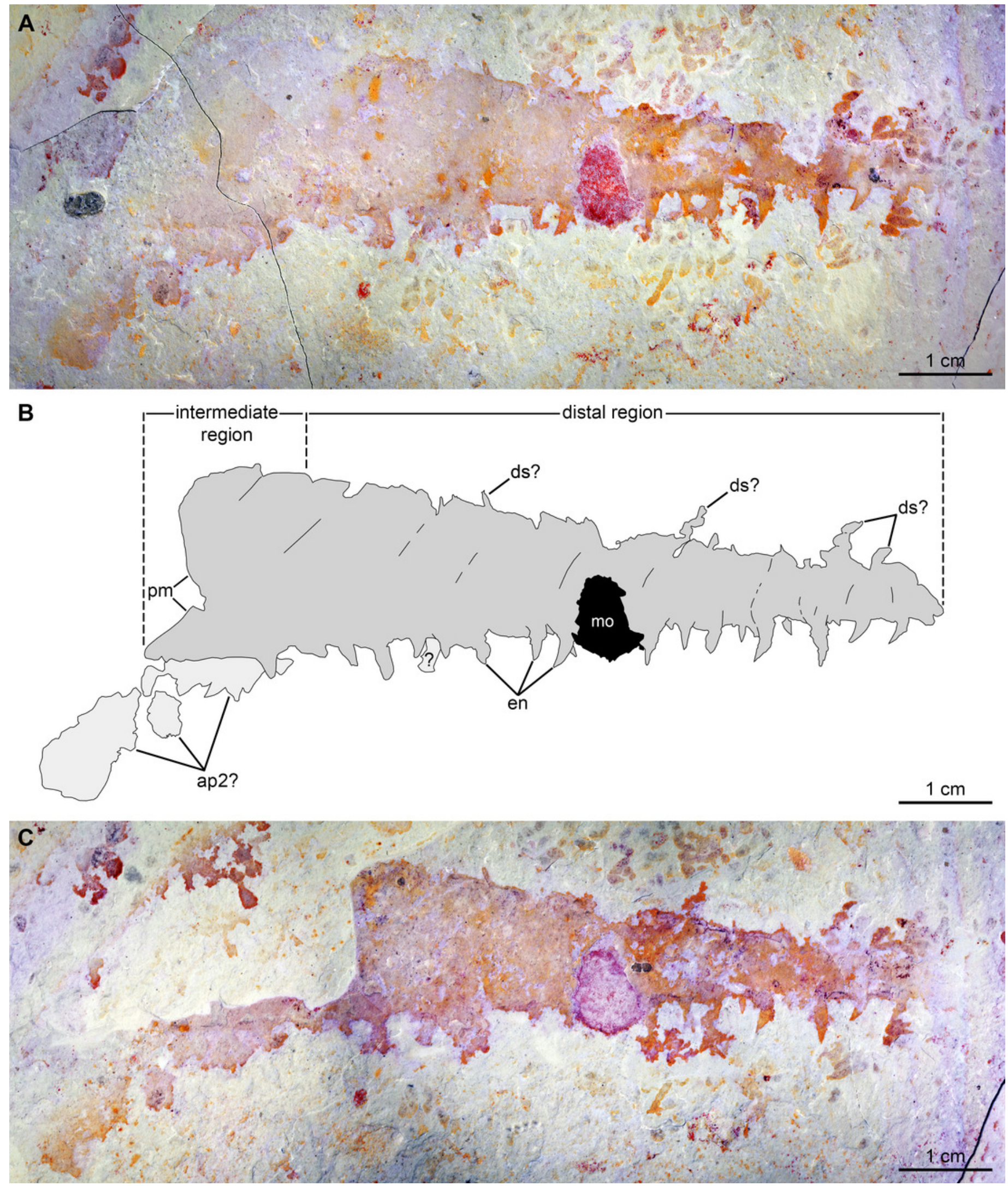


\section{Figure 10}

Figure 10. Examples of pelagic components of the Marjum Biota (Cambrian: Drumian) from the House Range of Utah, USA.

(A) Agnostoid Itagnostus interstrictus, UMNH.IP5621. (B) Medusiform fossil, UU07021.03 (from Cartwright et al. 2007). (C) Radiodont Peytoia, USNM.PAL374593. (D) 'Bivalved arthropod' Tuzoia, KUMIP153917a (credit: Julien Kimmig). (E) 'Bivalved arthropod' Perspicaris, UMNH.IP6323. (F) 'Bivalved arthropod' Branchiocaris, KUMIP204797 (credit: Julien Kimmig).

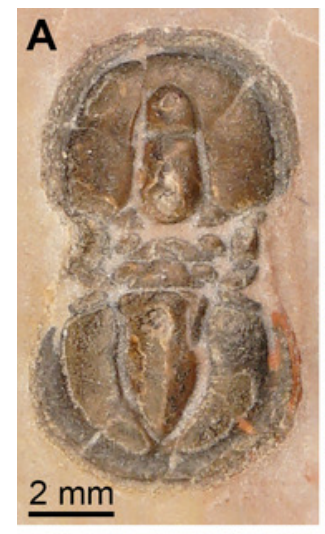

E
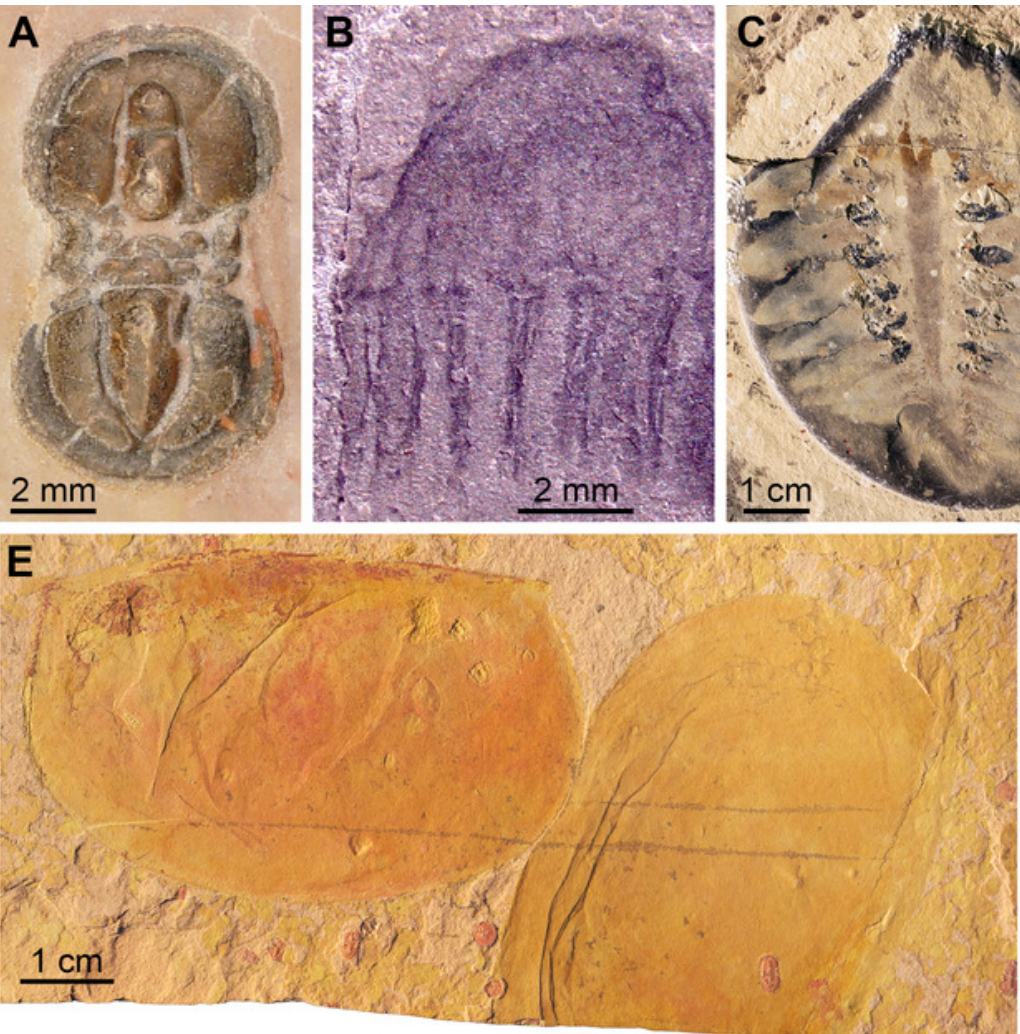
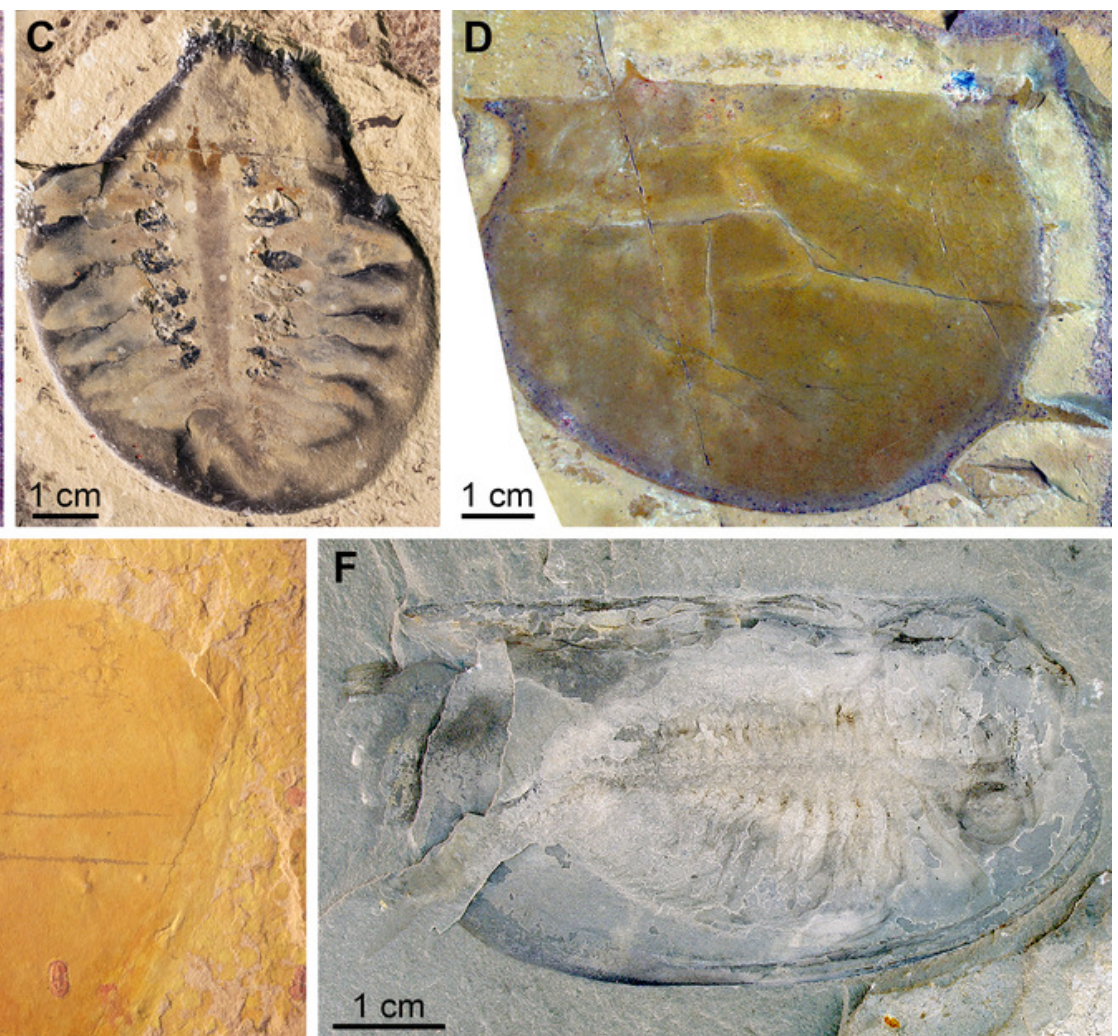


\section{Table $\mathbf{1}$ (on next page)}

Comparison of the oral cone and trunk morphologies of select hurdiid radiodonts 
1 Table 1. Comparison of the oral cone and trunk morphologies of select hurdiid radiodonts.

\begin{tabular}{|c|c|c|c|c|c|}
\hline Anatomical structure & Aegirocassis & Cambroraster & Hurdia & Peytoia & Buccaspinea \\
\hline \multicolumn{6}{|l|}{ Oral cone } \\
\hline Symmetry & Unknown & Tetraradial & Tetraradial & Tetraradial & Tetraradial? \\
\hline Marginal teeth & Unknown & $\begin{array}{l}\text { Large, three per } \\
\text { plate }\end{array}$ & Small & Small & $\begin{array}{l}\text { Large, hooked, } \\
\text { three per plate }\end{array}$ \\
\hline Inner teeth & Unknown & Present & Present & Absent & Absent \\
\hline Body shape & $\begin{array}{l}\text { Oblong } \\
\text { (weak to no } \\
\text { posterior tapering) }\end{array}$ & $\begin{array}{l}\text { Diamond } \\
\text { (strong posterior } \\
\text { tapering) }\end{array}$ & $\begin{array}{l}\text { Oblong } \\
\text { (weak to no } \\
\text { posterior tapering) }\end{array}$ & $\begin{array}{l}\text { Diamond } \\
\text { (strong posterior } \\
\text { tapering) }\end{array}$ & $\begin{array}{l}\text { Oblong } \\
\text { (weak to no } \\
\text { posterior tapering) }\end{array}$ \\
\hline \multicolumn{6}{|l|}{ Trunk flaps } \\
\hline Flap-bearing segments ${ }^{1}$ & 11 & 8 & $6-9$ & 11 & $11+$ \\
\hline Lateral flap morphology & Small, triangular & Small, triangular & Small, triangular & Broad, triangular & Broad, triangular \\
\hline & $\begin{array}{l}\text { With transverse lines } \\
\text { across entire width }\end{array}$ & $\begin{array}{l}\text { With transverse lines } \\
\text { across entire width }\end{array}$ & $\begin{array}{l}\text { With transverse lines } \\
\text { across entire width }\end{array}$ & $\begin{array}{l}\text { With transverse lines } \\
\text { across anterior half }\end{array}$ & $\begin{array}{l}\text { With transverse } \\
\text { lines across entire } \\
\text { width }\end{array}$ \\
\hline Dorsal flaps & Present & Absent & Present & Present & Absent \\
\hline Posterior body region & Unknown & $\begin{array}{l}\text { Tailfan, two pairs of } \\
\text { caudal lobes }\end{array}$ & $\begin{array}{l}\text { Tailfan, one pair of } \\
\text { caudal lobes }\end{array}$ & $\begin{array}{l}\text { No tailfan } \\
\text { Trapezoidal } \\
\text { termination }\end{array}$ & Unknown \\
\hline References & Van Roy et al. 2015 & $\begin{array}{l}\text { Moysiuk \& Caron, } \\
2019\end{array}$ & $\begin{array}{l}\text { Daley et al. } 2009 \text {, } \\
\text { 2013; Van Roy et al. } \\
2015\end{array}$ & $\begin{array}{l}\text { Whittington \& } \\
\text { Briggs 1985; Van } \\
\text { Roy et al. } 2015\end{array}$ & This study \\
\hline
\end{tabular}

$2 \quad{ }^{1}$ does not include reduced anterior segments bearing lamellar bands known in Cambroraster and Hurdia.

3

4 


\section{Table 2 (on next page)}

Table 2. Taxonomic diversity and fossil richness of the radiodont faunas from the Cambrian Konservat-Lagerstätten of western Utah, USA.

Fossil richness is based on published data. Abbreviations used: $A B$, articulated body $(+/-$ complete), $C E$, central carapace element, FA, frontal appendage, LE, lateral carapace element, OC, oral cone. 
1 Table 2. Taxonomic diversity and fossil richness of the radiodont faunas from the Cambrian 2 Konservat-Lagerstätten of western Utah, USA. Fossil richness is based on published data. 3 Abbreviations used: AB, articulated body (+/- complete), CE, central carapace element, FA, 4 frontal appendage, LE, lateral carapace element, OC, oral cone.

5

\begin{tabular}{|c|c|c|c|c|}
\hline Genus & Wheeler-HR & Wheeler-DM & Marjum & Weeks \\
\hline Amplectobelua & $\begin{array}{l}\text { Amplectobelua } \text { cf. A. stephenensis } \\
\text { - } 1 \text { FA } \\
\text { (Lerosey-Aubril et al. 2020) }\end{array}$ & Absent & Absent & Absent \\
\hline Anomalocaris & Absent ${ }^{1}$ & Absent ${ }^{2}$ & Absent & $\begin{array}{l}\text { Anomalocaris aff. } \text { A. } \\
\text { canadensis }-5 \mathrm{FA} \\
\text { Anomalocaris sp. }-1 \mathrm{FA} \\
\text { (Lerosey-Aubril et al. 2014) }\end{array}$ \\
\hline Buccaspinea & $\begin{array}{l}\text { B. cooperi? - } 1 \mathrm{FA} \\
\text { (Lerosey-Aubril et al. 2020a, their } \\
\text { 'Hurdia sp. nov. A'; this study) }\end{array}$ & Absent & $\begin{array}{l}\text { B. cooperi-1 } \mathrm{AB} \\
\text { (This study) }\end{array}$ & Absent \\
\hline Caryosyntrips & $\begin{array}{l}\text { C. serratus }-2 \text { FA } \\
\text { (Pates \& Daley, 2017; } \\
\text { Lerosey-Aubril et al. 2020a) }\end{array}$ & $\begin{array}{l}\text { C. durus - } 2 \text { FA } \\
\text { (Pates \& Daley, 2017) }\end{array}$ & $\begin{array}{l}\text { Caryosyntrips camurus - } 2 \text { FA } \\
\text { (This study) }\end{array}$ & Absent \\
\hline Pahvantia & $\begin{array}{l}\text { Pa. hastata-1 FA, } 14 \mathrm{CE}, 9 \mathrm{LE} \\
\text { (Robison \& Richards, 1981; } \\
\text { Lerosey-Aubril \& Pates, 2018; } \\
\text { Lerosey-Aubril et al. 2020a) }\end{array}$ & $\begin{array}{l}\text { Pa. hastata }-1 \mathrm{CE} \\
\text { (Lerosey-Aubril \& Pates, 2018) }\end{array}$ & $\begin{array}{l}\text { Pa. hastata-3 CE } \\
\text { (This study) }\end{array}$ & Absent \\
\hline Peytoia & $\begin{array}{l}\text { Pe. nathorsti }-1 \mathrm{FA}, 3 \mathrm{OC} \\
\text { (Conway Morris \& Robison 1982; } \\
\text { Pates et al. 2018a) }\end{array}$ & Absent & $\begin{array}{l}\text { Pe. nathorsti-1 AB, } 1 \mathrm{OC} \\
\text { (Briggs \& Robison, 1984; } \\
\text { Pates et al. 2018a) }\end{array}$ & Absent \\
\hline Stanleycaris & $\begin{array}{l}\text { Stanleycaris sp. - } 1 \text { FA } \\
\text { (Pates et al. 2017) }\end{array}$ & Absent & Absent & Absent \\
\hline New genus & Absent & $\begin{array}{l}\text { Anomalocarididae gen. et sp. } \\
\text { nov. }-1 \mathrm{FA} \\
\text { (Halgedahl et al. 2009) }\end{array}$ & Absent & Absent \\
\hline
\end{tabular}

